\title{
SOFT IMPACTS ON AEROSPACE STRUCTURES
}

\author{
Serge Abrate \\ Mechanical Engineering and Energy Processes \\ Southern Illinois University \\ Carbondale, IL 62901-6603 \\ abrate@engr.siu.edu
}

\begin{abstract}
This article provides an overview of the literature dealing with three types of soft impacts of concern for the aerospace applications, namely impacts of rain drops, hailstones and birds against aircraft. It describes the physics of the problem as it has become better understood through experiments, analyses, and numerical simulations. Some emphasis has been placed on the material models and the numerical approaches used in modeling these three types of projectiles.
\end{abstract}

Keywords: impact, rain, birds, hailstones, aircraft

\section{1- INTRODUCTION}

This article deals with the impact of rain drops, hailstones, and birds on aerospace structures. These three types of impacts are usually considered to be soft impacts even if it is difficult to define what constitutes a soft impact as opposed to a hard impact [1]. Soft impacts are sometimes defined as impacts in which the stresses generated far exceed the strength of the projectile but are far below the strength of the target [2] [3]. Often publications dealing with hard impacts such as those occurring when a tool is dropped on a composite structure state that their analytical or numerical models are applicable to bird strikes and hail strikes. The following will show that this is not the case. 
Current research emphasis is on the development of efficient approaches for numerical simulation that requires adequate models of the material behavior and efficient numerical methods for handling the large deformations and flow of soft projectiles. In many cases the projectile behaves as an inviscid fluid and sometimes artificial viscosity is introduced to avoid oscillations in the predicted response. Other material models are also used for the projectile while for the target elastic models, viscoelastic models and various plasticity models are used. Modeling a highly deformable projectile is challenging when using Lagrangian or Eulerian descriptions of the deformation. Approaches combining these two continuum descriptions are found to be more efficient and the Smooth Particle Hydrodynamics (SPH) method that considers the material as a series of particles appears as the favorite approach for modeling bird strikes in particular. The article focuses on soft impacts on aircrafts and in particular the impacts due to rain, birds and hailstones.

\section{2- LIQUID IMPACT}

Research on this topic started in 1928 with an investigation of the erosion caused by the collapse of cavities on the surface of steam turbine blades [4]. Since then, the scope broadened to include rain erosion on acrylic materials for aircraft transparencies [5] and forward facing airplane components [6], particularly those made out of composite materials. Currently, rain erosion is also a significant issue for the leading edges of wind turbine blades made out of composites with either glass or carbon fiber reinforcement [7] and require special coatings [8]. In addition, to these obvious reasons to study liquid impacts, we will see that at typical impact velocities birds behave like fluid during impact.

Cook [4] discusses the erosion caused by the collapse of cavities on the surface of steam turbine blades. Considering a column of water of impacting a rigid surface with a velocity $\mathrm{V}$, the kinetic

energy of a layer of thickness $\Delta \mathrm{h}$ prior to impact is $\frac{1}{2} \rho \mathrm{V}^{2} \mathrm{~A} \Delta \mathrm{h}$ where $\mathrm{A}$ is the cross-sectional area of the column and $\rho$ is the density of the fluid. After impact, the velocity of the fluid is zero and the kinetic energy has been converted into potential energy $\frac{1}{2} \mathrm{pe}_{\mathrm{v}} \mathrm{A} \Delta \mathrm{h}$ where the volumetric strain $e_{v}=p \beta$. Equating these two energies gives the pressure $p=V \sqrt{\rho / \beta}$. The compressibility $\beta$ is the inverse of the bulk modulus $B$ and $\sqrt{B / \rho}=C$, the speed of sound in the fluid. This pressure is usually written as 


$$
\mathrm{p}=\rho \mathrm{CV}
$$

and is commonly called the water hammer pressure. The bulk modulus of water is $2.2 \mathrm{GPa}$ and its density is $1000 \mathrm{~kg} / \mathrm{m}^{3}$ so $\mathrm{c}=1483 \mathrm{~m} / \mathrm{s}$. Cook considered impact velocities in excess of 120 $\mathrm{m} / \mathrm{s}$. When $\mathrm{V}=120 \mathrm{~m} / \mathrm{s}$, Eq. 1 predicts a water hammer pressure of $178 \mathrm{MPa}$ which is of the same order of magnitude than the yield strength of engineering materials. The wave velocity $\mathrm{C}$ is related to the acoustic wave velocity $\mathrm{C}_{\mathrm{a}}$ and the particle velocity by $C=C_{a}+k V$ where $\mathrm{k}$ is approximately equal to 2 when $\mathrm{V}<1000 \mathrm{~m} / \mathrm{s}$ as indicated in [9]. Therefore, at high impact velocities, the shock wave velocity is significantly higher than the acoustic wave velocity.

Another view of this problem is that the motion of the fluid is governed by the wave equation and that, after impact against the rigid surface, a compressive wave propagates into the fluid with a velocity $\mathrm{C}$ and the pressure behind the wave front is the water hammer pressure (Eq. 1). When the water column impacts an elastic half-space, two waves propagate away from the interface: one into the fluid and the other into the solid. The water hammer pressure is

$$
p=\frac{z_{1} z_{2}}{z_{1}+z_{2}} V=\frac{\rho_{1} c_{1} \cdot \rho_{2} c_{2}}{\rho_{1} c_{1}+\rho_{2} c_{2}} V
$$

where $z_{1}=\rho_{1} c_{1}$ and $z_{2}=\rho_{2} c_{2}$ are the mechanical impedances of the liquid and the solid [10]. Eqs. 1, 2 predict the pressures during the initial phase of the impact between a liquid and a solid. As soon as the impact initiates and the shock wave starts to propagate upwards, relief waves initiating at the periphery of a cylindrical liquid projectile start to propagate inwards (Fig. 1). For water jet of radius $r$ impacting a solid surface, the impact phase ends when these release waves reach the central axis at time $\mathrm{t}=\mathrm{r} / \mathrm{C}$. That marks the end of the high pressure phase. After that, the flow can be considered to be incompressible. For incompressible flows, on a stream line, Bernoulli's principle states that $\frac{\mathrm{V}^{2}}{2}+\mathrm{gz}+\mathrm{p} / \rho=$ constant . When applied to the stream line along the axis of the projectile we found that the stagnation pressure is

$$
\mathrm{p}_{\mathrm{s}}=\rho \mathrm{V}^{2} / 2
$$


After that the pressure at the stagnation point falls to $p_{s}=\frac{1}{2} \rho V^{2}$. The ratio of the water hammer pressure (Eq. 1) to the stagnation pressure $p / p_{s}=2 C / V$ is always large which indicates the importance of the initial stage of the liquid-solid impact.

For a spherical water drop impacting a rigid surface [11] [12], the contact radius at the end of the high-pressure stage and the duration of that high-pressure stage are $r=R V / C$ and $\tau=3 \mathrm{RV} / 2 \mathrm{C}^{2}$. The pressure in the compressed region behind the shock wave is not uniform and is highest just behind the contact edge. The pressure at first contact (Eq. 1) increases to approximately three times that value right before jetting [13]. The average pressure during the impact phase is given by $\mathrm{p}=\frac{1}{2} \alpha \rho C V$ where the factor $1 / 2$ is due to the spherical shape of the drop and the factor $\alpha$ tends to one for high impact velocities (Engel [14], 1955).

As the initial high pressure phase of the impact nears its end, the contact radius $r_{e}$ increases with a velocity equal to the shock velocity [15] (Fig. 2). The contact ends when the angle $\beta$ reaches the critical value $\beta_{\mathrm{c}}=\sin ^{-1}(\mathrm{~V} / \mathrm{C})$. Prior to this instant, the contact radius expands faster that the radius of the high pressure zone (Fig. 3.-a). Then, the shock wave detaches from the impacted surface and a relief wave propagates towards the inside of the high pressure zone (Fig. 3.b). Finally, a jet develops as the water is free to escape (Fig. 3.c)

In a semi-infinite target, the impact generates three types of waves: a longitudinal compressive wave (P-wave) propagating radially with a velocity $\mathrm{c}_{\mathrm{p}}$, a shear wave ( $\mathrm{S}$-wave) propagating with a velocity $\mathrm{c}_{\mathrm{s}}$, and a Rayleigh surface wave propagating along the surface with a velocity $\mathrm{c}_{\mathrm{R}}$ (Fig. 4a). In general $c_{R}$ is very close to $c_{s}$. In brittle materials such as glass fractures on the impacted surface are thought to be induced by the surface wave while failures inside the material below the impacted area are attributed to tensile radial stresses following the passage of the shear wave [11]. For impacts on a plate, the compressive wave reflect from the stress-free back face as a tensile wave (Fig. 4.b) which leads to a significant damage called scabbing or spalling [16].

Rain erosion is a function of $\mathrm{n}$, the number of impacts per unit area. Experiments showed that, after an incubation period, the mass loss per unit area $m$ appears to increase linearly with $n$ between two values of $n: n_{i}$ marking the end of the incubation period and $n_{f}$ marking the end of 
the region in which $\mathrm{m}$ increases linearly with $\mathrm{n}$. Springer and Yang [17] present results on rain erosion of coated and uncoated fiber reinforced composite materials.

Studies of the effects of rain drop impacts on optically transparent materials (glass [11] [16], PMMA [10] [13] [18] [19] [20] [21], transparent natural rubber [18] ...) but also on infrared transparent materials such as zinc sulfide ( $\mathrm{ZnS})$ [22] [23][24] [25] or zinc-selenide (ZnSe) [23] are available. A finite element simulation of the impact of a $2 \mathrm{~mm}$ diameter rain drop on $\mathrm{ZnS}$ target [6] at normal and oblique incidence $\left(45^{\circ}\right)$ and high velocity $(305 \mathrm{~m} / \mathrm{s})$ gives a detailed distribution of radial tensile stresses during the impact. It also shows a strong interaction between the drop and a highly deformable target made out of polyurethane.

Liquid impacts on composite materials are studied in [19] [26] [27] [28] in connection with rain erosion. Recent experimental studies show that the presence of air between the liquid drop and a solid surface leads to deformation of the bottom surface of the drop and air entrapment during the impact [29] [30]. Contact occurs along a ring enclosing a thin disk of air [31]: a fact that was discussed by Cook [4].

\section{3- BIRD STRIKES}

Bird strikes on airplanes and helicopters are regular costly events that can cause loss of aircrafts and the loss of lives. The threat to flying aircraft and the basic understanding of bird-aircraft collisions gained from extensive experimental studies is discussed in subsection 3.1. In recent years, much effort and significant progress has been made to develop material models, numerical approaches, and software to simulate the bird strikes on various components of an airplane. Material models for birds are described in 3.2 and applications to bird strikes on plates, engine components, windshields and other aircraft components are discussed the remainder of this section.

\section{1- Introduction to bird strike problems}

\subsection{1- The threat to flying aircraft}

Bird strikes have been a serious threat to aircrafts since the beginning of aviation history. The earliest documented bird strike to a powered aircraft occured on 7 September 1905 in Dayton, $\mathrm{OH}$ during a flight demonstration by Orville Wright. Thorpe [32] shows that from 1912 to 2002, 
bird strikes were responsible for at least 55 fatal accidents killing 276 people and destroying 108 civil aircrafts. For transport planes and executive jets bird strikes caused accidents primarily when birds were ingested into the engines ( $76 \%$ of the cases) or when they hit the windshield (7\%). For general aviation airplanes, the situation is very much different. Accidents were caused when birds hit the windshield (54\%), engines (13\%), wings (12\%). The difference in the effect of bird strikes between the two different types of aircraft is that: larger aircraft generally are equipped with jet engines and general aviation aircraft are not; (2) stricter requirements are placed on the design of windshield for transport airplanes. These trends tend to explain why a significant portion of the research on bird strikes deals with either the impacts on jet engine blades or on windshields. Statistics indicate that, for helicopters, the areas most likely to be damaged by bird impacts are the windshield (39\%), the rotor (11\%) and the nose (11\%) [33]. Impacts with birds have increased dramatically in recent years due to significantly large increases of large birds (more than $3.6 \mathrm{~kg}$ ) and to some extent because of increases in air traffic [34].

Bird impacts occur at high speeds and introduce severe loads. Considering an impact velocity of $500 \mathrm{ft} / \mathrm{s}(152.4 \mathrm{~m} / \mathrm{s})$ and a typical density of $56.19 \mathrm{lb} / \mathrm{ft}^{3}\left(900 \mathrm{~kg} / \mathrm{m}^{3}\right)$, Eq. 3 predicts that the pressure applied is $1515 \mathrm{psi}(10.45 \mathrm{MPa})$. If, as indicated in [35], this pressure is applied on a 20 $\mathrm{in}^{2}$ area, this results in a force in excess of 30,000 lb. At this velocity, the kinetic energy of a $4 \mathrm{lb}$ $(1.814 \mathrm{~kg})$ bird is $21.1 \mathrm{~kJ}$. This is a very large amount of energy that has to be absorbed without causing catastrophic failure.

Migratory Canada geese ingested into the engines of US Airways Flight 1549 that crash landed in the Hudson River in New York City on 15 January 2009 [36]. Several non-lethal techniques to reduce bird-aircraft collisions have been proposed. Fernández-Juricic [37] tested the hypothesis that an aircraft color scheme might play a role in bird-strike frequency. It was found that for birds brighter colors would contrast more against the sky than darker colors and, while not conclusive, empirical evidence suggested that brighter aircraft were associated with lower bird-strike rates. Blackwell and Bernhard [38] tested the hypothesis that during daylight, captive birds exposed to an approaching ground-based vehicle exhibiting pulsing 250-W white aircraft landing lights would initiate avoidance behavior more quickly than birds experiencing an oncoming vehicle with nonpulsing (steady) or no lights. Of the five types of birds considered 
(captive brown-headed cowbirds, Canada geese, European starlings, herring gulls, and mourning doves), only cowbirds exhibited a response to the landing lights, but not consistently.

\subsection{2- Basic understanding from experimental results}

Wilbeck [2] presented a detailed account of the literature on soft impact prior to 1978 and a basic understanding of bird impacts on various structures was gained through a several experimental studies. Birds or bird substitutes of different sizes and impact velocities were considered: 60 to $150 \mathrm{~g}$ at $350 \mathrm{~m} / \mathrm{s}$ in [39], 71 to $85 \mathrm{~g}$ at $200 \mathrm{~m} / \mathrm{s}$ in [40], $60 \mathrm{~g}$ to $4 \mathrm{~kg}$ at 50 to 300 $\mathrm{m} / \mathrm{s}$ [41], 1.8 and $3.6 \mathrm{~kg}$ in [42], $450 \mathrm{~g}$ at up to $300 \mathrm{~m} / \mathrm{s}$ in [43]. Oblique impacts are considered in [41], [43], [44]. It was found that:

- Real birds behave as fluids during impact at velocities larger than $75 \mathrm{~m} / \mathrm{s}$ [44] or $100 \mathrm{~m} / \mathrm{s}$ $[2]$.

- Typically, the impact consists of four phases: (1) the shock phase of initial impact in which the pressure reaches the water hammer pressure; (2) the shock pressure decay phase; (3) the steady flow phase during which the pressure along the axis is the stagnation pressure $p=\rho V^{2} / 2$; and (4) the termination phase in which the fluid moves parallel to the surface of the target and the pressure is zero.

In experiments, substitutes are usually preferred to real birds. Gelatin with $10 \%$ porosity was found to be an adequate substitute for bird material [41] [44]. The porosity is achieved by the uniform distribution of phenolic microballoons [44]. Other materials have been used to build bird simulants. For example, synthetic ballistic gel already employed as muscle tissue surrogate [45]. Lavoie et al [46] provide a detailed list of ingredient and a procedure for making substitute birds with water, ballistic gelatin, and smaller amounts of other ingredients. In Shupikov et al [47] a bird analog is made of silicon models the bird's muscular tissue and plastic ball fillers and in [48] four parts water to one part of bovine hide gelatine was used to substitute bird..

End on straight cylinders are the best shape to simulate ends on impacts of real birds [41] and a length to diameter ratio of two is recommended [44]. Challita and West [43] found that, when birds strike side-on, no region of steady flow pressure can be detected. The Hugoniot pressure 
decay process is still continuing as the trailing edge of the bird reaches the target surface. The density of the bird and its dimensions are usually determined from expressions of statistical analyses of various bird populations. For example, in [49], the bird's density and its torso diameter are given by $\rho=959-63 \log _{10} \mathrm{~m}$ and $\log _{10} \mathrm{~d}=-1.095+0.335 \log _{10} \mathrm{~m}$ in terms of its mass $\mathrm{m}$. This information about the geometry, the density and the diameter of the bird is used to design bird substitutes for experiments or to for numerical modeling.

This early work provides a basic understanding of bird impacts normal to a rigid surface. Oblique impacts are more complicated and for impacts on deformable structures the interaction between the deformation of the projectile and that of the target should be accounted for. Section3.2 describes models for the constitutive behavior of birds during impact, impacts on rigid and deformable plates are discussed in Section 3.2. Overviews of current work on bird impacts on turbofan engine blades, windshields, and leading edges of wings or tail sections are given in Sections 3.3-3.5.

\section{2- Constitutive equations}

One of the challenges in the simulation of a soft projectile such as a bird is to select a model to represent the behavior of that projectile: the bird in this case. Experimental studies have shown that the bird behaves like a fluid during impact and that the impact has both a shock phase and a flow phase. This suggests that this fluid model should be a compressible fluid.

Using a general approach that can be used for both solids and fluids, the Cauchy stress tensor $\sigma_{\mathrm{ij}}$ is split between a hydrostatic part and a deviatoric part

$$
\sigma_{\mathrm{ij}}=-\mathrm{p} \delta_{\mathrm{ij}}+\mathrm{s}_{\mathrm{ij}}
$$

where $\mathrm{p}=-\sigma_{\mathrm{kk}} / 3=-\left(\sigma_{11}+\sigma_{22}+\sigma_{33}\right) / 3$ is the hydrostatic pressure, and $\mathrm{s}_{\mathrm{ij}}$ is the deviatoric stress tensor. The pressure is related to the deformation by an equation of state and $\mathrm{s}_{\mathrm{ij}}$ can be described in various ways depending on the material to be modeled. For an inviscid fluid such as water $\mathrm{s}_{\mathrm{ij}}=0$ and many simulations assume that the bird is also inviscid.

\subsection{1- Polynomial equation of state}

Equations of state describe the pressure-volume behavior. The polynomial equation of state 


$$
\mathrm{p}=\mathrm{C}_{0}+\mathrm{C}_{1} \mu+\mathrm{C}_{2} \mu^{2}+\mathrm{C}_{3} \mu^{3}
$$

where $\mu=\left(\rho / \rho_{0}\right)-1$ is the relative change in density and $C_{0}-C_{3}$ are constants determined from experiments. Usually, $\mathrm{C}_{0}=0$ and often only the second term is retained (e.g. [50] [51] [52]). $\mathrm{C}_{1}$ is the bulk modulus of the material and is also called K. Additional terms are often added to Eq. 5 (e.g. [52],[53], [54])

$$
\mathrm{p}=\mathrm{C}_{0}+\mathrm{C}_{1} \mu+\mathrm{C}_{2} \mu^{2}+\mathrm{C}_{3} \mu^{3}+\left(\mathrm{C}_{4}+\mathrm{C}_{5} \mu+\mathrm{C}_{6} \mu^{2}\right) \mathrm{E}
$$

Usually these added terms are not used in modeling birds. However Eq. 6 can be used to model the surrounding air by taking $\mathrm{C}_{0}=\mathrm{C}_{1}=\mathrm{C}_{2}=\mathrm{C}_{3}=\mathrm{C}_{6}=0$ and $C_{4}=C_{5}=\gamma-1$ where $\gamma=1.4$ is the ratio of the specific heats [42] [54].

It is often said that the bird is modeled as water mainly because the same equation of state is used and the densities are close. However, it was found that birds can be thought of as a mixture of water and a small percentage of air. Selezneva [55] considered a material model with polynomial EOS. The constants $\mathrm{C}_{1}-\mathrm{C}_{3}$ for 0,10 and $15 \%$ porosity are given in Table 1 and, for these values, the pressure plotted versus the relative density up to $1200 \mathrm{MPa}$ in Fig. 5 shows that a small change in porosity can have a significant effect.

\subsection{2- Tait's equation of state}

Tait's equation of state proposed in 1888 [56] is widely used to model the behavior of water [57][58] [59] and is usually written as

$$
\mathrm{p}=\mathrm{B}\left[\left(\frac{\rho}{\rho_{\mathrm{o}}}\right)^{\mathrm{n}}-1\right]
$$

when $\rho>\rho_{o}$. The constant $B$ is related to the wave velocity by $B=\rho_{o} c^{2} / n$. For water $n=7.15$, $\rho_{\mathrm{o}}=1000 \mathrm{~kg} / \mathrm{m}^{3}, \mathrm{~B}=2.984 \times 10^{6} \mathrm{~Pa}$. Tait's equation of state is widely used to model the behavior of birds during impact. Eq. 7 is also called Murnaghan's EOS in many publications in reference to a 1944 article by that author [60] .

\subsection{3- Equation of state derived from the Rankine-Hugoniot relations}


Considering a shock wave moving with a velocity $\mathrm{u}_{\mathrm{s}}$ in a fluid initially at rest, the particle velocity $\mathrm{u}_{1}=0$ ahead of the shock wave and $\mathrm{u}_{2}=\mathrm{u}_{\mathrm{p}}$ behind the shock wave (Fig. 6-a). In a coordinate system moving with the wave front, the situation is as shown in Fig. 6-b. The equations for conservation of mass and conservation of momentum are

$$
\rho_{\mathrm{o}} \mathrm{u}_{\mathrm{s}}=\rho\left(\mathrm{u}_{\mathrm{s}}-\mathrm{u}_{\mathrm{p}}\right) \quad \mathrm{p}_{1}+\rho_{\mathrm{o}} \mathrm{u}_{\mathrm{s}}^{2}=\mathrm{p}_{2}+\rho\left(\mathrm{u}_{\mathrm{s}}-\mathrm{u}_{\mathrm{p}}\right)^{2}
$$

as in [2]. Combining these two equations gives the Hugoniot pressure

$$
p_{\mathrm{H}}=\mathrm{p}_{2}-\mathrm{p}_{1}=\rho_{\mathrm{o}} \mathrm{u}_{\mathrm{s}} \mathrm{u}_{\mathrm{p}}
$$

which is the same as Eq. 1 accounting for changes in the shock wave velocity. Eq. 8.a can be rewritten as

$$
\frac{\mathrm{u}_{\mathrm{p}}}{\mathrm{u}_{\mathrm{s}}}=1-\frac{\rho_{\mathrm{o}}}{\rho}=\eta
$$

where the variables $\eta$ and $\mu$ are defined in terms of the densities before and after the shock by $\eta=1-\frac{\rho_{0}}{\rho}=\mu /(1+\mu)$. For a linear (Hugoniot) relationship between the shock velocity and the particle velocity

$$
\mathrm{u}_{\mathrm{s}}=\mathrm{c}_{\mathrm{o}}+\mathrm{ku}_{\mathrm{p}}
$$

Eq. 10 gives $u_{p}=u_{s} \eta$, substituting into Eq. 11 gives $u_{s}(1-k \eta)=c_{o}$ and substituting into Eq. 8.b gives

$$
\mathrm{p}=\rho_{\mathrm{o}} \mathrm{c}_{\mathrm{o}}^{2} \eta /(1-\mathrm{k \eta})^{2}
$$

This equation is the simplest of several Mie-Gruneisen equations of state and it is often used to model the behavior of birds. A third order Taylor series expansion of Eq. 11 in terms of $\mu$ gives the following expressions for the constants in the polynomial equation of state (Eq. 5)

$$
\mathrm{C}_{1}=\rho_{\mathrm{o}} \mathrm{c}_{\mathrm{o}}^{2}, \quad \mathrm{C}_{2}=(2 \mathrm{k}-1) \mathrm{C}_{1} \quad \mathrm{C}_{3}=(\mathrm{k}-1)(3 \mathrm{k}-1) \mathrm{C}_{1}
$$

These formulas are used to estimate the constants $\mathrm{C}_{1}-\mathrm{C}_{3}$ in the polynomial equation of state (Eq. 4) when only the density and $c_{o}$ are known. It is often assumed that the slope of the linear Hugoniot relationship $\mathrm{k}=2$ for water. 
Using higher order polynomial functions on the right hand side of the Hugoniot relationship (Eq. 12) leads to more complex expressions for the Hugoniot pressure. For example, with the cubic polynomial function $\mathrm{u}_{\mathrm{s}}=\mathrm{C}+S_{1} \mathrm{u}_{\mathrm{p}}+S_{2} u_{p}^{2}+S_{3} u_{p}^{3}$ the Hugoniot pressure becomes

$$
p_{H}=\rho_{o} C^{2} \eta /\left\{1-S_{1} \eta-S_{2} \eta^{2} \mathrm{u}_{\mathrm{s}}-S_{3} \eta^{3} u_{s}^{2}\right\}^{2}
$$

The three equations of state discussed here (Eqs. 5, 7, 12) are used almost exclusively to model the material behavior of birds during impact. An alternative is to specify the pressure volume relationship in tabular form as a few authors have elected to do.

\subsection{4- Viscous fluid models}

For Newtonian fluids, the deviatoric stresses $\mathrm{s}_{\mathrm{ij}}$ are directly proportional to the deviatoric strain rates $d_{i j}^{\prime}$

$$
s_{i j}=2 \mu d_{i j}^{\prime}
$$

where $\mu$ is the viscosity of the fluid, $\mathrm{d}_{\mathrm{ij}}^{\prime}=\mathrm{d}_{\mathrm{ij}}-\frac{1}{3} \mathrm{~d}_{\mathrm{kk}} \delta_{\mathrm{ij}}$, and the rate of deformation tensor is defined in terms of the velocity components $v_{i}$ as $d_{i j}=\left(\partial v_{i} / \partial x_{j}+\partial v_{j} / \partial x_{i}\right) / 2$. In conjunction with an equation of state such as Eq. 4, for example, this Eq. 13 is used for describing the behavior of birds impacts in several studies [54] [61] [62] [63] [64] [65] [66]. In some cases a small viscosity term like this is introduced to prevent oscillations in numerical simulations.

\subsection{5- Elastoplastic models}

For some soft impacts, large deformations occur and a consistent formulation is required. To handle large rotations, and Brockman and Held [64] used the Jaumann stress rate tensor $s_{\mathrm{ij}}^{\mathrm{J}}=$ $\dot{\mathrm{s}}_{\mathrm{ij}}-\mathrm{s}_{\mathrm{ik}} \mathrm{W}_{\mathrm{kj}}+\mathrm{s}_{\mathrm{jk}} \mathrm{W}_{\mathrm{ki}}$ where $\dot{\mathrm{s}}_{\mathrm{ij}}$ is the material time derivative of the Cauchy stress $\sigma_{\mathrm{ij}}$. The velocity gradient is split into a symmetric tensor $\mathbf{D}$ called the rate of deformation tensor and an anti-symmetric tensor $\mathbf{W}$ called the spin tensor. In terms of the components of the velocity 
vector $v$, the components of $\mathbf{D}$ and $\mathbf{W}$ are $\mathrm{d}_{\mathrm{ij}}=\left(\mathrm{v}_{\mathrm{i}, \mathrm{j}}+\mathrm{v}_{\mathrm{j}, \mathrm{i}}\right) / 2$ and $\mathrm{w}_{\mathrm{ij}}=\left(\mathrm{v}_{\mathrm{i}, \mathrm{j}}-\mathrm{v}_{\mathrm{j}, \mathrm{i}}\right) / 2$. The material remains elastic as long as the equivalent von Mises stress $\sigma_{e}=\sqrt{\frac{3}{2} s_{i j} s_{i j}}$ is less than the current yield strength

$$
\sigma_{\mathrm{y}}=\sigma_{\mathrm{y}}^{\mathrm{o}}\left[1+(\dot{\mathrm{e}} / \mathrm{D})^{1 / \mathrm{p}}\right]+\mathrm{H} \varepsilon_{\mathrm{p}}
$$

which depends on the static yield strength in tension $\sigma_{\mathrm{y}}^{\mathrm{o}}$, the effective strain rate $\dot{\mathrm{e}}=\sqrt{\frac{2}{3} \mathrm{~d}_{\mathrm{ij}}^{\prime} \mathrm{d}_{\mathrm{ij}}^{\prime}}$, the hardening modulus $\mathrm{H}=\mathrm{EE}^{\prime} /\left(\mathrm{E}-\mathrm{E}^{\prime}\right), \varepsilon_{\mathrm{p}}$ is the effective plastic strain, and the constants $\mathrm{D}$ and $\mathrm{p} . \mathrm{E}$ is the elastic modulus and $\mathrm{E}^{\prime}$ is the slope of the stress-strain curve past the yield point (Fig. 7). When strain rate effects are neglected [67], è is assumed to be zero in Eq. 14 .

For the elastic part of the deformation, the time derivative of the deviatoric Cauchy stress is related to the deviatoric part of the rate of deformation by $s_{\mathrm{ij}}^{\mathrm{J}}=2 \mathrm{G} \mathrm{d} \mathrm{d}_{\mathrm{ij}}^{\prime}$. Plastic flow is expected to occur when $\sigma_{\mathrm{e}}>\sigma_{\mathrm{y}}$ and in that case the stresses are returned to the yield surface using the radial return correction $s_{\mathrm{ij}} \leftarrow s_{\mathrm{ij}} \sigma_{\mathrm{y}} / \sigma_{\mathrm{e}}$. In [64], the updated plastic strain is evaluated using $\varepsilon_{\mathrm{p}} \leftarrow \varepsilon_{\mathrm{p}}+\left(\sigma_{\mathrm{e}}-\sigma_{\mathrm{y}}\right) /(3 \mathrm{G}+\mathrm{H})$ and the pressure $\mathrm{p}$ is evaluated using a polynomial equation of state. The effective plastic strain can also be evaluated using $\varepsilon_{\mathrm{p}}=\int_{0}^{t}\left(\frac{2}{3} \dot{\varepsilon}_{i j}^{p} \dot{\varepsilon}_{i j}^{p}\right)^{1 / 2} d t^{\prime}$ where the plastic strain rate $\dot{\varepsilon}_{i j}^{p}$ is the difference between the total strain rate $\dot{\varepsilon}_{i j}$ and the elastic strain rate $\dot{\varepsilon}_{i j}^{e}$ as in [67]. In [67], the pressure-volume relationship is given in terms of the bulk modulus $\mathrm{K}$ and the ratio of the current volume $\mathrm{v}$ to the initial volume $\mathrm{v}_{\mathrm{o}}$. That is, $\mathrm{p}=$ $-\mathrm{K} \ln \left(\mathrm{v} / \mathrm{v}_{\mathrm{o}}\right)$.

\section{3- Numerical models for soft projectiles}

An important consideration for numerical simulations is the choice of the way the deformation is described. In a Lagrangian description, nodes in a computational mesh correspond to specific material particles. The mesh deforms with the material and that has some advantages in tracking free surfaces and interfaces between materials but there are difficulties with large deformations that result in severe mesh distortion. The Eulerian description uses a fixed grid and the material moves relative to it. It requires a grid large enough to cover the region where the material is initially but also where it might be in the future. There are difficulties in tracking the location of 
free surfaces and interfaces. The Arbitrary Lagrangian Eulerian (ALE) description the grid may be moved and/or deformed in a prescribed way. This approach allows to handle cases with more distortion than the Lagrangian description and with more resolution than with an Eulerian approach since the region to be meshed will be much smaller [68]. In addition to these meshbased methods, meshless methods have been developed including the SPH method [69]. The main difference is that the formulation is focused on the motion of particles instead of the deformation of meshes.

Bird impact problems are solved using a Lagrangian approach in [61] [62] [65] [70] [71] [72] [73] [74], the ALE approach in [52] [53] [54] [75] [76] [77] [78] [79] [80] [81] [82] [83], and a variant of the ALE approach called coupled Eulerian Lagrangian (CEL) is used in [72] [84] [85] [86] [87] [88] [89]. The Eulerian approach is rarely used in bird impact problems [90] because a large grid is needed which leads to high computational costs. A discussion of these three methods and examples are given in [91] [92] [93] [94].

The SPH method is used in bird impact simulations [33] [45] [49] [54] [71] [79] [82] [95] [96] [97] [98] [99] [100] [101] [102] [103] [104] [105] [106] [107] [108] [109] [110] [111] [112] [113]. To obtain and accurate description of the pressure applied on the surface of the target the SPH model requires a large number of particles: 1856 particles in [97], 13,871 in [79], 35,000 in [103] [114], or 65,000 in [71]. Other meshless methods are available but besides the SPH method, it appears that only the discrete element method is used for bird impact problems in [115]

\section{4- Bird impact on plates}

Often tests are conducted using rigid plates as a target in order to better understand the mechanics of soft impacts and generate data to validate numerical simulations. Many numerical analyses use the impact against a rigid surface for validation purposes (e.g. [46] [65] [89] [103] [116] [117][118]). Impacts on deformable plates are also considered to study the interaction between the deformation of the soft body and that of the structure. 


\subsection{1- Bird impact on rigid plates}

The maximum pressure is generated during the first phase of the impact and can be determined using the expression for the Hugoniot pressure (Eq. 9). During the flow phase the pressure on the axis of the projectile during a normal impact is the stagnation pressure $p=\rho V^{2} / 2$,

It is known that "If the natural period of the impacted structure is long compared with the duration of the impact, the impact may be considered to be an impulsive event" so that the impulse is the only parameter required to analyze the response [41]. This is the case for many bird-windshield collisions. Considering the conservation of momentum during normal impact, the impulse applied on a rigid surface $I=\int \mathrm{Fdt}=\mathrm{mV}$. Ref. [41] assumes that the bird behaves like a fluid, the impact begins when the leading edge of the bird first touches the target and ends when the trailing edge reaches the target, and that the bird does not decelerate during impact. Then the impact duration is equal to the length of the projectile divided by the impact velocity $(\Delta \mathrm{T}=\mathrm{L} / \mathrm{V})$. The average force applied on the target given by $\mathrm{F}=\mathrm{I} / \Delta \mathrm{T}$ is $\mathrm{F}=\mathrm{QAV}{ }^{2}$.

The pressure distribution due to the normal impact of a water jet can be estimated by the expression given by Banks and Chandraskhara

$$
p=\frac{1}{2} \rho V^{2} \exp \left\{-\zeta_{1}(r / a)^{2}\right\}
$$

or by that of Leach and Walker

$$
p=\frac{1}{2} \rho V^{2}\left\{1-3\left(\frac{r}{\zeta_{2} a}\right)^{2}+2\left(\frac{r}{\zeta_{2} a}\right)^{3}\right\}
$$

where $\zeta_{1}=0.5$ and $\zeta_{2}=2.58, \mathrm{r}$ is the radius and $\mathrm{a}$ is the radius of the cylinder [2]. Fig. 7 shows how the pressure spreads beyond the initial radius of the cylinder, the difference between the predictions of Eq. $(15,16)$ is small. This distribution is similar to that obtained in the numerical analysis of Airoldi and Cacchione [119].

For oblique impacts on a rigid surface (Fig. 9.a), the back of the cylinder is assumed to keep moving with the same velocity $\mathrm{V}$ through the effective length $\mathrm{L}_{\text {eff }}=\mathrm{L}+\mathrm{D} / \tan \theta$. The contact duration is $\Delta t=\mathrm{L}_{\text {eff }} / \mathrm{V}$ and experiments [41] verified that the normal component of the momentum transferred to the plate $\int \mathrm{Fdt}=\mathrm{mV} \sin \theta$. The impulse momentum relation can be written as $m V \sin \theta=F_{\text {avg }} \cdot \Delta t$. The average force is estimated by $F_{\text {avg }}=m V^{2} \sin \theta / L_{\text {eff }}$. Barber 
et al [41] observed that the impact force varies in a triangular fashion (Fig. 9.b) with a maximum force $\mathrm{F}_{\max }$ occurring at $\Delta \mathrm{t} / 5$ so $\mathrm{F}_{\max }=2 \mathrm{~F}_{\mathrm{avg}}$. These are general trends followed by experimental results.

\subsection{2- Bird impact on deformable plates}

Uncoupled loads models assume only small to moderate deformations of the structure prior to catastrophic failure. This way the loads applied to the structure are not affected by its deflections and the analysis is greatly simplified. Following [41], such an analysis is based on four assumptions: (1) the target is completely rigid; (2) The bird behaves as a fluid during impact; (3) the component of bird momentum normal to the target is completely transferred to the target; (4) there is no deceleration of the bird during impact. Uncoupled loads models can successfully predict the response in the case of normal impacts but, for oblique impacts, changes in load location during the impact are significant and are not accounted for in these models [120]. Current state of the art simulations consider bird impacts as a coupled problem and, with the availability of software, the main issue in the development of an adequate model is the proper description of the material behaviors and the discretization of the bird.

Rosenblatt et al [121] simulated the short term response to the impact of a $3 \mathrm{oz}(85 \mathrm{~g})$ sphere of water (radius 1.07 in or $2.73 \mathrm{~cm}$ ) with a velocity of $675 \mathrm{ft} / \mathrm{s}(206 \mathrm{~m} / \mathrm{s})$ impact either a rigid surface or a thin plate at normal or oblique incidence. Results for the normal impact on a 0.136 in $(3.45 \mathrm{~mm})$ thick stainless steel plate show a significant deflection of the plate that significantly reduces the applied force. The maximum deflection $152 \mu \mathrm{s}$ after the start of the impact is larger than $10 \mathrm{~mm}$ and permanent deformations remain after the interaction with the water ceases.

Experiments showed that oblique impacts on deformable metallic plates produce two types of deformations depending on the type of response induced: (1) locally rigid target usually deform quasi-statically, the entire target participates in the deformation; (2) locally deforming targets refers to cases in which the bending deformation is limited to a relatively small region surrounding the impact and has not reached the boundaries [41]. The first case is called a boundary controlled impact which occurs when the projectile is much heavier than the target while the second case is a wave controlled impact and it occurs when the projectile is significantly lighter than the target [122]. 
Bird impacts often induce permanent deformation for materials that deform plastically and the yield strength is strain rate depend. A few expressions used to describe this strain rate dependence are used extensively and they are discussed in the following. Airoldi and Cacchione [119] study bird impact on circular polycarbonate plates. This material is assumed to be elastoplastic and the yield stress for that material is assumed to vary with strain rate as

$$
\sigma_{y} / \sigma_{y o}=1+(\dot{\varepsilon} / D)^{1 / p}
$$

where $\sigma_{y}$ is the dynamic yield strength, $\sigma_{y o}$ is the static yield strength, and p and D are constants. Strain rate effects on the yield strength of metals including strain rate effects is also described by

$$
\sigma_{y}=\left[a+b\left(\epsilon_{p}\right)^{n}\right]\left[1+(\dot{\varepsilon} / D)^{1 / p}\right]
$$

where $\epsilon_{p}$ is the effective plastic stress, $\dot{\varepsilon}$ is the strain rate, and a,b, n, D, and $\mathrm{p}$ are material constants. The second bracket is the Cowper-Symmonds factor accounting for strain rate. Eq. 18 is used for 7075 aluminum alloy [123], steel and aluminum alloy [95], 2024-T3 aluminum facesheets in a sandwich plate [124]

The behavior of metals subjected to plastic deformations with high strain rate and temperature effects is often described by the empirical Johnson-Cook relation

$$
\sigma_{y}=\left[a+b\left(\epsilon_{p}\right)^{n}\right]\left[1+c \ln \left(\dot{\varepsilon} / \dot{\varepsilon}_{o}\right)\right]\left(1-T^{* m}\right)
$$

where $\sigma$ is the stress, $\epsilon_{p}$ is the effective plastic strain, $\dot{\varepsilon}$ is the strain rate, $\dot{\varepsilon}_{o}$ is a reference strain rate $\left(\dot{\varepsilon}_{o}=1 \mathrm{~s}^{-1}\right.$ in [101]), $T^{* m}=\left(T-T_{r}\right) /\left(T_{r m}-T_{r}\right)$ where $T_{r}$ is the room temperature and $T_{m}$ is the melting point of the material. The First bracket gives the shape of the curve, the second bracket accounts for strain rate effects, and the last term accounts for the effect of temperature. Constants $\mathrm{a}, \mathrm{b}, \mathrm{c}, \mathrm{m}, \mathrm{n}$ are determined for each material. The Johnson-Cook model was used for aluminum alloys LY-12 and 2024-T3 in [101]

Simulations of bird strikes on composite plates can be found in [76] [87] [89] [106][107]. With cohesive elements, Heimbs and Bergmann were able to predict the size of delaminations and examined the effect of preloads on damage induced by bird strikes [89]. 


\section{5- Bird impacts on engine blades}

It is often said that bird impacts are the major cause of blade damage for aircraft engines. Many types of birds can cause significant engine damage and their size varies greatly: doves with a mass of $120 \mathrm{~g}$ [125], american kestrels with a mass of $120 \mathrm{~g}$ [125], snowy owls [125], Eastern Canada geese with a mass of $7 \mathrm{~kg}$ [126], starlings typically weighting $3 \mathrm{oz}$ (85 g) and flocking in large numbers [126]. Ref [126] mentions several incidents between a commercial aircraft and a flock of starlings or gulls that left hundreds of dead birds on the runway. On 26 July 2005, at least one turkey vulture was struck by the external fuel tank on the Space Shuttle Discovery during launch at the Kennedy Space Center in Florida [125]. The first major accident with fatalities in which bird-ingestion was a contributing factor occurred in October, 1960 when a Lockheed Electra ingested a large number of starlings and sustained partial power loss on three of its four engines. The aircraft crashed into Boston Harbor. This event led to the introduction of certification requirements for engines demonstrating flocking-bird ingestion capability [127].

Shown here as an idealized right cylinder, the bird moves towards the fan with a velocity $\bar{V}_{a}$ which is the velocity of the airplane while the fan rotates at high speeds (Fig. 10). The velocity of the bird relative to the rotating blades is $\bar{V}_{\text {relative }}=\bar{V}_{a}-\bar{V}_{t}$ where $\bar{V}_{t}$ is the linear velocity of the blade. The figure shows how two consecutive blades slice the bird into three pieces along planes parallel to the direction of the relative velocity. The idealized slice in the middle impacts the second blade shown in Fig. 10 and slides along its surface all the way to the trailing edge. Similarly, the top piece will impact the first blade and the bottom piece will hit a third blade not shown in the figure. Several situations arise depending on the size of the bird, the spacing of the blades and the velocities but several blades can be impacted by a single bird (This is clearly an oblique impact on a curved surface that should be analyzed as a three-dimensional problem [3]. The impact is most severe on the leading edge (or slicing edge) of the blade which may have to be reinforced by metal in the case of composite fan blades.

Analytical approaches [128] can simulate bird impacts on a single rotating turbofan blade but in general the problem is more complex and requires a numerical approach to model a full fan and the casing around it. As indicated in Fig. 10, soft projectiles are split into several impactors that come in contact with three or four blades [53] [112] [129]. Because of the damage induced by the impact, blade tips impact and slide against the casing which can cause failure of the case 
[129]. A progressive damage simulation of the entire fan stage predicted the detachment of a large number of blades resulting from a bird strike, in accordance with experimental results [114].

Birds are generally modeled as inviscid fluids with an equation of state relating the pressure to the relative change in volume or density. Usually, the behavior of the bird is described either by polynomial EOS [53] [62] [65][103] or the Tait EOS [99] [108]. The simple EOS $p=C_{1} \mu$ is used to model the behavior of the bird in several simulations of impact against fan blades [53] [82] [114] [129]

With rotating blades, centrifugal effects lead to significant deformation and initial stresses prior to impact. Generally a preliminary nonlinear analysis is performed to initialize stresses and strains in the blade prior to the impact simulation [53] [82] [83] [112][114] [129].

Most investigations on bird impacts with turbofan engines focus on impacts against rotating blades but two other engine components have also been studied. A spinner is an aerodynamic cone, a fitted over a propeller hub or at the centre of a turbofan engine [112]. Results for bird impacts at $100 \mathrm{~m} / \mathrm{s}$ at a $60^{\circ}$ angle on a spinner rotating at $7800 \mathrm{rpm}$ show that significant damage can be induced and important differences were observed depending on whether the spinner was rotating or stationary. Designs were developed for spinners to deflect the bird upon impact instead of having it trapped into the pocket formed during the deformation of spinner [111]. Anghileri et al [102] [109][110] examine bird impact damage onto turbofan-engine intakes and show examples of experimental and numerical results. The displacements from that pre-analysis are applied as initial conditions for the impact analysis

\section{6- Bird impacts on windshields}

Bird strikes on transparencies are a major threat for both commercial and military aircrafts. Several publications present photographic evidence of severe damage to aircraft canopies by bird impact including complete perforation [130], [131]. The canopies of some military aircrafts are made out of polycarbonate [64] [73] [130] [132]. Often it consists of a single layer but it can also be made of several layers. For example, McCarty [132] studies canopies with 4 layers of polycarbonate joined by three silicone interlayers. The stress-strain behavior of that material is 
nonlinear and tests at $25,40,80,100^{\circ} \mathrm{C}$ indicate that this behavior is strongly affected by temperature [73]. Canopies are also made of polymethyl methacrylate (PMMA). Historically, PMMA has often been called acrylic glass and many studies of birdstrikes on transparencies made with that material are available [67] [74] [80][132] [133] [134].

In the most basic construction, laminated glass for aircraft windshields consists of two glass panels joined by a polyvinyl-butyral (PVB) interlayer (e.g. [104]). More complex constructions can be used. For example, Refs. [104] [135] consider five layer laminates with three glass layers and two polyvinyl-butyral (PVB) interlayers.

\subsection{1- Constitutive models for transparencies}

In the basic windshield configuration with two glass panels joined by a polyvinyl-butyral (PVB) interlayer (e.g. [104], [136]), the glass layers are assumed to be elastic and failure is determined using the von Mises yield criterion while the yield strength is assumed to vary with strain rate according to the Cowper-Symmonds law (Eq. 17). In [33] [104] [136] the instantaneous shear modulus is taken to vary as

$$
G(t)=G_{\infty}+\left(G_{o}-G_{\infty}\right) e^{-\beta t}
$$

From [136], typical values of the material properties taken are $\mathrm{G}_{\mathrm{o}}=330 \mathrm{MPa}, G_{\infty}=0.69 \mathrm{MPa}$, and $\beta=12.6 \mathrm{~s}^{-1}$. With this value of $\beta$, the shear modulus does not vary much during a typical impact which is why, in some analyses, PVB is assumed to be elastic. The deviatoric stresses $s_{i j}$ and the deviatoric strains $\mathrm{e}_{\mathrm{ij}}$ are related by

$$
s_{i j}=2 \int_{0}^{t} G(t-\tau) \dot{e}_{i j}(\tau) d \tau
$$

and the volumetric behavior of PVB is assumed to be linear ( $\left.p=-K \varepsilon_{k k}\right)$ in [136] or to follow an EOS given in tabular form [104].

Tests by Hooper et al [137] showed that the behavior of PVB can be represented by the generalized Maxwell model (Fig. 11) in which the shear relaxation modulus is given as a function of time t by the Prony series

$$
G(t)=G_{\infty}+\sum_{i=1}^{n} G_{i} e^{-t / \tau_{i}}
$$


$G_{\infty}$ is the long term modulus, $G_{i}$ and $\tau_{i}$ are the shear moduli and relaxation times for each of the the Maxwell elements in parallel. At time $\mathrm{t}=0$, the instantaneous shear modulus is

$$
G_{o}=G_{\infty}+\sum_{i=1}^{n} G_{i}
$$

Numerical values of $G_{i} / G_{o}$ and $\tau_{i}$ for $i=1-6$ in [137] show that $G_{i}$ is small and the relaxation times are much larger that the duration of typical impacts when $\mathrm{i}$ is larger than two. The same model (Eq. 21) is used in [138] [139]. The same expression can be used for the bulk relaxation modulus $\mathrm{K}(\mathrm{t})$ with a long term modulus $K_{\infty}, K_{i}$, and a different set of relaxation times $\tau_{i}$ [139]. Experimental results for PVB [137] [140] show that the behavior is linear for strains below $20 \%$. The constitutive equations for this linear generalized Maxwell model are

$$
\sigma_{i j}(t)=\int_{o}^{t} 2 G(t-\tau) \frac{d e_{i j}}{d \tau} d \tau+\delta_{i j} \int_{o}^{t} K(t-\tau) \frac{d \varepsilon_{k k}}{d \tau} d \tau
$$

where $e_{i j}$ is the deviatoric strain and $\varepsilon_{k k}$ is the volumetric strain [141]. Eq. 19 is obtained when $\mathrm{n}=1$ in Eq. 21 and Eq. 20 is the first term in Eq. 23 dealing with deviatoric stresses. Nonlinear constitutive models for describing the large deformations can be developed considering the interlayer material to be hyperelastic following some of the well-known models from rubber elasticity (e.g. [140][142]). This approach gives the nonlinear first term in Eq. 21. To account for rate effects, the other terms in the Prony series are added [142].

Laminated glass for windshield applications also uses transparent polymers such as polymethyl methacrylate (PMMA), polycarbonate (PC), or polyurethane (PU). Nonlinear viscoelastic material models can be used for these materials (e.g. [134]) 


\subsection{2- Constitutive models for birds}

In the analysis of bird strikes on windshields, the bird is usually modeled as an inviscid fluid $\left(s_{\mathrm{ij}}=0\right.$ in Eq. 4). Many studies use a polynomial equation of state while others use the MieGruneisen type EOS. In [49] [104] [135], the pressure is given in tabular form as a function of the volumetric strain $\varepsilon_{\mathrm{v}}$ which is the natural $\log$ of the relative volume. A one term Taylor series expansion gives $\varepsilon_{\mathrm{v}}=-\mu$.

Another approach is to model the bird as a viscoelastic fluid. The volumetric behavior is represented by a linear relationship (Eq. 5 where $C_{1}$ is the only non-zero term) with a bulk modulus $\mathrm{C}_{1}=\mathrm{K}=60 \mathrm{MPa}$ and the deviatoric deformations by a viscoelastic shear model (Eq. 19) with $\mathrm{G}_{0}=6.2 \mathrm{MPa}, G_{\infty}=0.3 \mathrm{MPa}$, and $\beta=0.5 \mathrm{~s}^{-1}$ as in [143].

\subsection{3- Impact response}

Refs. [104] [135] consider five layer laminates with three glass layers and two polyvinyl-butyral (PVB) interlayers. All layers are $4 \mathrm{~mm}$ thick for a total thickness of $20 \mathrm{~mm}$. The $1.8 \mathrm{~kg}(4 \mathrm{lb})$ bird in that study has a density $950 \mathrm{~kg} / \mathrm{m}^{3}$ and is idealized as a right circular cylinder with a recommended length to diameter ratio $\mathrm{L} / \mathrm{D}=2$ and a $106 \mathrm{~mm}$ diameter. This study pointed out the need to accurately model the supporting frame ant its interaction with laminated glass.

Some investigations consider more than the bird and the canopy during impact. For example, in [35] a two degree of freedom model (Fig. 12) representing the first mode of transparency and the first mode of the supporting frame that is attached to the airframe is subjected to sine pulse duration of $0.5 \mathrm{~ms}$. That pulse represents a typical load induced by a bird strike. The idea behind this simplified model is to examine the role that the frame can play in absorbing energy which can hardly be accomplish by the canopy alone.

Belytschko [144] studied bird strikes on canopies of military aircrafts. A simulation of the complete scenario of a bird-strike event is presented including the bird-canopy impact, the canopy-pilot impact, and the resulting response of the pilot. It includes a "simplified model" of the upper body including the spine and the head that consists of 50 masses connected by springs with axial, bending and torsional stiffnesses. 


\section{7- Bird impact on aircraft leading edges}

Bird strikes on aircrafts occur on wings, radome shields [52] and vertical and horizontal stabilizers in addition to impacts on engine blades and windshields. Photographs show significant damage induced by bird impacts on leading edges of wings (Doubrava [131] , [145] ), on Pitot tubes (Doubrava [131]) and on the fuselage of airplanes and helicopters [36]. Regulations (FAR 25.571) require that airplanes must be capable of successfully completing a flight after an impact with a $1.81 \mathrm{~kg}(4 \mathrm{lb})$ bird at the expected cruising velocity.

Simulations of bird strikes on the leading edges of aircraft wings are presented in several publications in which the leading edge is made out of: (1) laminated composite materials [87] [118] [146] [147]; (2) fiber metal laminates (FML) [97] [148] [149] [150], (3) a tensor skin laminate [151] [152]; (4) a sandwich construction with a FML outside skin, an aluminum honeycomb core, and an aluminum inside skin [49] [105] or other sandwich structures [52].

Composite materials are used extensively in both commercial and military aircrafts. In these materials, impacts are known to induce damage that will significantly affect the structure's load carrying capability. The challenge in the simulation is to predict the damage induced by the bird strike and in particular to predict the size and location of the debonding between plies. In [118] a $1.8 \mathrm{~kg}$ bird is modeled as an inviscid fluid and only the $\mathrm{C}_{1}$ term is retained in the polynomial equation of state so that the pressure is equal to the bulk modulus times $\mu$, the relative change in volume. The motion of the bird substitute is described using the SPH method. The target is a wing leading edge profile made of glass fabric/epoxy composite with a $[0 / 45]_{2 S}$ layup modeled with eight stacked shell elements to predict the size delaminations. Bayandor et al [147] addressed the same problem modeling the bird using the SPH method and the Tait or Murnaghan equation of state. Delamination is modeled using cohesive elements with a bilinear cohesive law between plies, the laminated being modeled using a stacked shell approach [118] [146] [147]. The onset of delamination is predicted using the mixed mode fracture criterion $\left(G_{I} / G_{I C}\right)^{n}+$ $\left(G_{I I} / G_{I I C}\right)^{n}=1$. $G_{I}$ and $G_{I I}$ are mode I and mode II the strain energy release rates and the subscript $\mathrm{c}$ indicates their critical values. Often, the exponent $\mathrm{n}$ is taken to be one by some authors or two by others. Once delamination is initiated, its growth is controlled by the cohesive law. In these three references delamination is assumed to be controlled by the transverse normal stress at the interface. 
Fibre metal laminates (FML) are of laminated composite materials consisting of alternating plies and fiber reinforced epoxy. The concept of FMLs originated at Fokker in the Netherlands in the 1950s [148]. Glass-based FMLs under the name commercial name GLARE can be found on the Boeing 777, the Bombardier Learjet 125 and the upper fuselage of the A380 [148]. The constitutive model for the composite plies includes two damage parameters to account for loss of rigidity under transverse and shear loading and also accounts for strain rate effects [148] [149]. The laminate is modeled using a stacked shell finite element approach with tied contact connections to model delaminations. The behavior of the bird is modeled using Tait's EOS and the SPH method is used for its discretization [97] [150].

The tensor skin concept was initially to increase the survivability of helicopter crashes on water surfaces [153] and is now considered for use in aircraft wing leading edges to resists bird strikes [151] [152]. The typical configuration three types of plies: the 'carrying', 'tensor' and 'cover' plies (Fig. 13). During normal operations, load carrying plies transfer aerodynamic loads to the ribs and provide the required stiffness of the wing leading edge. Tensor plies, consist of folded loops that unfold when high loads are applied as in the case of bird impacts. Tensor plies are usually composite plies with high molecular weight polyethylene (Dynema) fabric reinforcement. The cover ply just provides a smooth external surface for aerodynamic purposes. Under large impacts the tensor skin unfolds and acts as a membrane to stop the projectile.

Numerical analyses of bird impacts on the trailing edge of aircraft wings are presented in several references [72] [84] [85] [86] [113].

Bird impacts on the leading edges of vertical stabilizers were analyzed in [50] [154]. The bird is modeled using solid brick elements with a linear equation of state $p=K \mu$ where the bulk modulus $\mathrm{K}=2200 \mathrm{MPa}$. The density, mass, and initial velocity of the bird are $950 \mathrm{~kg} / \mathrm{m}^{3}, 3.62 \mathrm{~kg}$ $(8 \mathrm{lb})$, and $129 \mathrm{~m} / \mathrm{s}$ (250 knots) respectively. The impact energy in this case is $30 \mathrm{~kJ}$. Bird impacts on horizontal tail plane leading edges were simulated in [155]

\section{4- HAIL IMPACT}

The risk of severe damage caused by the impact of hailstones on airplanes has long been recognized. Souter and Emerson [156] present an extensive review of 131 case histories from 
1938 to 1952 . Their findings are: (1) The leading edges of the wing and tail are the areas more susceptible to damage; (2) damage to the fuselage is usually confined to the nose and cockpit areas and windshields or canopies can be broken or cracked; (3) engine cowlings can be damaged like leading edges.

Hail impacts can occur either when the airplane is on the ground or in flight. For ground hail impacts the size of the hailstones can be estimated from historical records and their terminal velocities can also be predicted. Studies of the frequency distribution of maximum hailstone diameters started in 1899 and the data indicates that the probability of hailstones having a diameter larger than $25.4 \mathrm{~mm}$ ( 1 in) is just 0.07 [157]. In vertical fall, hailstones reach a terminal velocity when its weight is balanced by the air resistance. That is when $m g=\frac{1}{2} \rho_{\text {air }} \mathrm{CV}^{2} \mathrm{~A}$ where $\mathrm{g}$ is the gravitational acceleration, $\rho_{\mathrm{air}}$ is the density of the air, $\mathrm{C}$ is the drag coefficient. The mass of a spherical ice projectile $m=\pi \rho_{i} d^{3} / 6$ and its projected area is $A=\pi d^{2} / 4$. The terminal velocity can be written as

$$
\mathrm{V}=\left(\frac{4 \rho_{\mathrm{i}} \mathrm{g}}{3 \rho_{\mathrm{air}} \mathrm{C}} \mathrm{d}\right)^{1 / 2}=\mathrm{K} \sqrt{\mathrm{d}}
$$

Typically, the density of hailstones is $900 \mathrm{~kg} / \mathrm{m}^{3}$ [157], the density of air of $1.24 \mathrm{~kg} / \mathrm{m}^{3}, \mathrm{C}=0.45$ and $\mathrm{g}=9.81 \mathrm{~m} / \mathrm{s}^{2}$. Eq. 24 indicates that the kinetic energy of hailstones increases with $\mathrm{d}^{4}$ which is why many authors consider that size is the major factor affecting damage induced by hailstone impacts on crops and structures. Typically, hailstones have a mass of 63 grams and a velocity of $37.3 \mathrm{~m} / \mathrm{s}$ which gives a kinetic energy of $43 \mathrm{~J}$ (Alves [145] ). Inflight hail impacts occur when airplanes fly through a storm and in that case the impact velocity is essentially the velocity of the aircraft. For example, in Ref. [158] simulated the impact on hailstones as spherical masses of $99.6 \mathrm{~g}$ and a diameter of $60 \mathrm{~mm}$, yield stress of $17 \mathrm{MPa}$ and an ultimate tensile strain of 0.05 . For ground hail impacts, impact energies were either 90 or $136 \mathrm{~J}$. With the same hailstones inflight impacts at $225 \mathrm{~m} / \mathrm{s}(812 \mathrm{~km} / \mathrm{h})$ resulted in kinetic energy $2543 \mathrm{~J}$. 
The following discusses models for the constitutive behavior of ice and the damage induced by the impact of hailstones on both metallic and composite structures.

\section{1- Material model for ice impacts}

Selecting a model to describe the behavior of the projectile or the target during impact should be based on the physics of the problem and what is to be predicted. The compressive stress-strain behavior of ice is known to exhibit two types of behaviors: (1) ductile behavior for low strain rates and (2) brittle behavior at high strain rates [159]. During the ductile phase, strain hardening occurs and the maximum strength increases with strain rates, collapse occurs when the strain reaches $10 \%$ or more. The strain-rate hardening exponent $m=0.3\left(\sigma \propto \dot{\varepsilon}^{m}\right)$. When the ice becomes brittle is collapses when shortened by about $0.1 \%$ and the strength decreases with strain rate. The transition between the two regimes corresponds to the highest compressive strain. The same behavior is observed in tension [160]. With low velocity impacts, hailstones remain in one piece even if many cracks develop [161]. In that case the projectile can be thought to behave as a solid and "the microstructure (equiaxed or monocrystalline) does not seem to have a significant influence on the residual deformation of the plate. The ice clearly behaves as a solid during the impact because the plastic deformations of the plate under the impact spot produced by the impact are localized" [162]. On the other hand, "at a velocity significantly greater than that required to produce fracture in the ice, the mechanical properties become relatively insignificant, and the impact forces are governed by the shape and mass of the projectile" [163], suggesting that the ice behaves as a fluid.

\subsection{1- Ice as a brittle solid}

Schulson gives an extensive review dealing with the brittle failure of ice [164]. In several publications, ice is modeled as a brittle solid in which damage occurs when tensile strains develop [165]. This model is adapted from a previous model developed for concrete. The equivalent tensile strain is defined in terms of the principal strains $e_{i}$ as

$$
\bar{\varepsilon}=\sqrt{\sum_{i}\left(H_{i} e_{i}\right)^{2}}
$$


where Heaviside function $\mathrm{H}_{\mathrm{i}}$ is zero if $\mathrm{e}_{\mathrm{i}}<0$ and $\mathrm{H}_{\mathrm{i}}=1$ if $\mathrm{e}_{\mathrm{i}}>0$. Damage develops when $\bar{\varepsilon}$ reaches a threshold value $\mathrm{K}$ that depends on a single scalar damage variable $\mathrm{D}$. That can be written in the form of a failure criterion $f=\bar{\varepsilon}-K(D)=0$. A procedure for updating $\mathrm{D}$ is described that also include a damage delay effect [165]. The elastic properties of damaged elements in the model are reduced according to $\left\{\sigma_{i}\right\}=D\left[C_{i j}\right]\left\{\varepsilon_{i}\right\}$. A slightly different version is given in Chuzel et al [166].

\subsection{2 - Viscoelastic models}

Studies of the mechanical behavior of ice show that the stress-strain behavior is affected by strain rate which suggests the use of a viscoelastic models. Khoo et al [167] [168] describe a viscoelastic model that can be represented by a spring-mass model in one dimension. It consists of a Maxwell element in series with a Kelvin-Voigt element (Fig. 14) and produces three types of strain: the elastic strain $\varepsilon_{e}$, the viscous strain $\varepsilon_{v}$, and the delayed strain $\varepsilon_{d}$. This model is generalized to two dimensions [167] [168] and three dimensions [169].

Ice was also modeled as a viscoelastic material by Zamankhan to examine the impact of an ice ball with a stationary ice block [170] using the generalized Maxwell model described in Subsection 3.6.1 with a single term in the Prony series (Eq. 21). The simulation accurately predicted the coefficients of restitution obtained from experiments. The point was made that this model is inadequate for this problem because an unrealistic value of the relaxation time had to be used to achieve good agreement with experiments. Instead, it was shown that an elastoplastic model with strain-rate dependent yield strength provides a good fit to the experimental data while correctly modeling the physics of the problem.

\subsection{3- Elastoplastic models for ice impacts}

In some simulations, hail is modeled as a solid deforming plastically. Several issues must be addressed in developing such models including: (1) is ice isotropic or anisotropic?; (2) what is the yield or failure criterion?; (3) how is the post-yield behavior modeled? The behavior of ice has been studied extensively for many years and is known that there are many types of ice and that their internal structure is quite complex and affect their material properties. Many studies assume that on a macroscopic scale ice is isotropic and successfully analyze problems dealing 
with glaciers or with iceberg-ship interactions. In general, failure strengths in tension and compression are different and that should be accounted for in failure criteria for multiaxial loading.

To study the movement of glaciers, Nye [171][172] assumes that ice is an isotropic homogeneous solid and yielding does not depends on the hydrostatic stress and follows the Mises or the Tresca yield criterion. The von Mises yield criterion is expressed in terms of $J_{2}=s_{i j} s_{i j} / 2$, the second invariant of the deviatoric stress tensor, and the yield strength in tension $\sigma_{y}$ as

$$
f=J_{2}-\left(\sigma_{y}^{2} / 3\right)=0
$$

or, in terms of the equivalent (or von Mises) stress $\sigma_{e}=\sqrt{3 J_{2}}=\sqrt{\frac{3}{2} s_{i j} s_{i j}}$, Eq. 25 can be written as $\sigma_{e}-\sigma_{y}=0$. The strain energy density of an isotropic elastic material can be written in terms of only two invariants: $J_{2}$ and $I_{1}=\sigma_{11}+\sigma_{22}+\sigma_{33}$, the first invariant of the stress tensor. Experiments showed that for metals, yielding is independent of $I_{1}$ (or equivalently of the hydrostatic stress) and von Mises criterion is applicable. However, for many materials yielding does not depend on $J_{2}$ alone and a many other criteria have been introduced. Ref. [173] shows that most criteria can be written in terms of $J_{2}$ and $I_{1}$ and can be classified into four categories. Yield criteria for anisotropic materials are also discussed in [173].

Pernas-Sánchez et al [174] use the 1952 Drucker- Prager yield criterion

$$
f=\sqrt{J_{2}}-A-B I_{1}
$$

where $J_{2}=s_{i j} s_{i j} / 2$ is the second invariant of the deviatoric tensor, $I_{1}=\sigma_{11}+\sigma_{22}+\sigma_{33}$ is the first invariant of the stress tensor and the constants $\mathrm{A}$ and $\mathrm{B}$ depend on $\sigma_{t}$ and $\sigma_{c}$ the yield strengths in tension and compression: $A=\frac{2}{\sqrt{3}} \frac{\sigma_{c} \sigma_{t}}{\sigma_{c}-\sigma_{t}}, B=\frac{1}{\sqrt{3}} \frac{\sigma_{t}-\sigma_{c}}{\sigma_{c}+\sigma_{t}}$. Eq. 26 can be seen as the von Mises criterion in terms of the equivalent stress with an added $I_{1}$ term.

Based on experimental results from previous investigators, the yield strength of ice in compression was assumed to vary with strain rate but the yield strength in tension is expected to remain constant [174]. A non-associated plastic flow rule is developed to describe the inelastic 
behavior of ice. Other failure criteria are used to study iceberg-ship collisions but have not been used for hail impact simulations.

In some simulations, the deformations of the projectile may remain small and it is not necessary to distinguish between the different types of stress. To describe the deformation of soft impactors the approach described by Brockman et al (Section 3.2.5) is often used. Carney et al [175] extended this approach accounting for the fact that the strength of the ice is different in tension and compression and that the effect of strain rate are different in tension and compression.

\section{2- Hail damage}

Depending on the impact velocity, hailstone can experience large deformations and fragmentation. Several approaches have been used in the simulation of hailstones [176]: (1) the Lagrangian finite element formulation; (2) the Arbitrary Lagrangian Eulerian (ALE) method; and (3) the Smooth Particle Hydrodynamic (SPH) method. Using these three approaches on several hail impact problems it was concluded that the Lagrangian formulation is adequate only in the initial stages of the impact when the deformation of the ice does not cause severe element distortion. Difficulties were encountered when using the ALE method for the ice and a Lagrangian description of the structure. The SPH method is deemed to be the most efficient for this type of problem [176]. References [53], [146], [165], [166], [174], [177], [178], [179],[180], use it to model hailstones.

\subsection{1- Dent depth for hail impacts on metallic plates}

McNaughtan and Chisman [181] studied the effect of impact velocity, impact angle, plate material properties and thickness on the damage caused by one inch diameter hail at speeds up to $2500 \mathrm{ft} / \mathrm{s}(762 \mathrm{~m} / \mathrm{s})$. Under normal impact it was found that the dent depth varies linearly with impact velocity. For oblique impacts the dent depth varies with the normal component of the velocity. Hail penetration speed is proportional to the square root of the plate thickness. In [156], a model is developed to predict the dent depth produced by a mass $\mathrm{m}$ impacting a plate with a velocity $\mathrm{V}$. It is assumed that: 
1. a region with a radius $\mathrm{r}$ is deformed plastically into a conical shape and that $\mathrm{w}$, the depth of the dent, is small compared to $\mathrm{r}$

2. the deformation is resisted entirely by membrane forces and the deformation is purely plastic and irreversible.

3. All the kinetic energy of the ice sphere is expended by straining of the skin.

With these assumptions, the dent depth is given by

$$
w=V \sqrt{m} / \sqrt{2 \pi \sigma_{y} t}
$$

where $\mathrm{V}$ is the initial velocity of the sphere, $\mathrm{m}$ is its mass, $\sigma_{Y}$ and $\mathrm{t}$ are the yield stress and the thickness of the plate. Experimental results can be fitted by Eq. 27 when $1 / \sqrt{2 \pi}$ is replaced by a constant $\mathrm{k}$ determined by curve fitting [156]. Recalling the relationship between $\mathrm{V}$ and the diameter of the sphere (Eq. 24), Eq. 27 indicates that, for ground hail, w is proportional to the square of the diameter. Another analytical model for this problem was presented showing that the initial stage of permanent deformations dominated by bending and is followed by another stage controlled by membrane deformations [182]. Experiments show that in that second stage the dent depth increases linearly with the velocity of the projectile.

Fiber metal laminates (FMLs) are considered for use in primary aircraft structures. Experimental results show that permanent indentation of FML plates increases with the impact energy [183][184] [185]. Starikov [186] fitted experimental data for plates made out of aluminum or

fiber metal laminates by $w=A T^{B} /\left(\sigma_{y} t\right)$ where $\mathrm{T}$ is the initial kinetic energy of the projectile and $\mathrm{A}$ and $\mathrm{B}$ are determined by curve fitting.

\subsection{2-Hail impact on composite structures}

Foreign object impacts on composite structures generate several types of damage: fiber failures, matrix cracks, and delaminations [122,187,188]. During a hailstorm, a given part can be subjected to multiple impacts and the cumulative effect can be significant [189]. The effect of hail impact damage on the fatigue life of composites [190] and on the residual strength of sandwich panels [191] were shown to be significant. 
Fig. 7 in [192] shows photographs taken during the impact of a $42.7 \mathrm{~mm}$ diameter ice ball against a hard surface at $73.5 \mathrm{~m} / \mathrm{s}$ at four different times after initial contact: $0 \mu \mathrm{s}, 91 \mu \mathrm{s}, 182 \mu \mathrm{s}$, and $455 \mu \mathrm{s}$. The deformation of the sphere suggest that it behaves like a fluid. In addition, assuming that the back of the sphere moves at a constant $73.5 \mathrm{~m} / \mathrm{s}$, the impact duration is estimated by $\mathrm{t}=\mathrm{D} / \mathrm{V}$ is $585 \mu \mathrm{s}$, a value consistent with the results in [192]. In addition, experimental results indicate that the maximum impact force $\mathrm{F}$ varies linearly with the initial kinetic energy of the ball [192]. Dimensional analysis suggests that the force should be

proportional to the kinetic energy and inversely proportional to the diameter $\left(F \sim \frac{1}{2} m V^{2} / D\right)$. Similar photographs from Asp and Juntikka [193] for a $25 \mathrm{~mm}$ diameter sphere at $96 \mathrm{~m} / \mathrm{s}$ show what the authors call "local crushing and the subsequent fluid-like flow". Similar behavior is shown in [194], a study that focuses on impact-induced delaminations to laminated composites and in [161] where both experiments and simulations show the propagation of longitudinal cracks oriented along the direction of travel.

\section{5- CONCLUSION}

This article presents a review of the literature dealing with three types of soft impact problems of interest to the aerospace industry. It provides a list of 194 references that is far from exhaustive but gives a comprehensive view of the current state of knowledge for this type of soft impacts. The impact of rain drops lead to erosion or fracture. Bird strikes are severe threats due to the significant kinetic energy of the bird as it hits critical components of the airplane which should be able to complete its flight safely. Hailstones can cause significant damage since they also have significant kinetic energy levels before impact.

In each case, a basic understanding of the physics of the problem has been achieved through experimental and simple analytical approaches. This body of work makes it clear that such soft impact are significantly different than hard impacts like those due to tool drops on aircraft structures. The analysis should account for the fluid-like behavior of the projectiles and the kinetic energy to be dissipated is much larger in the case of bird strikes or hail impacts. In recent years, an increasingly large number of publications report on numerical simulations of this type of soft impacts. This is made possible by the availability of software capable of modeling the large deformations of the projectile using the SPH method or other approaches. That type of 
software also allows to experiment with different models for the constitutive behavior of the materials for the projectile and for the target. It was shown that plausible results can be obtained with inappropriate constitutive models in the case of ice impacts.

Numerical simulations of soft impacts are usually performed as a coupled problem: one numerical model for the projectile coupled with a numerical model for the target. This is sometimes referred to as a two-way coupling so that the projectile generates a load on the structure and in turn the deformation of the structure affects the motion of the projectile. Accurate analyses require a detailed discretization of both domains as discussed earlier. A more efficient approach might be what is called one-way coupling or an uncoupled approach. Essentially, it assumes that the loading generated by the impact can be determined assuming that the target is rigid so that the pressure distribution over its surface is calculated considering the deformation of the projectile only. Then, this load history is used to calculate the response of the structure. This approach is applicable when the deformation of the structure is small enough that it does not affect the deformation of the projectile or when the impact and the deformation of the structure occur on two different time scales. For the normal impact of a right cylinder on a rigid surface it is possible to actually predict the pressure distribution on that surface during the impact. Numerical simulations indicate that the situation more complex for oblique impacts and for the impact of spherical projectiles or projectiles of other shapes. A better understanding of these cases and an investigation of the possible use of uncoupled analysis could lead to more efficient simulations. When two-way coupling is required, it should be possible to obtain nondimensional results to predict spatial and temporal pressure distributions without having to perform a full analysis.

\section{Acknowledgements}

This work was supported in part by a grant from the Office of Naval Research, Solid Mechanics Program and by Southern Illinois University. 


\section{6- REFERENCES}

[1] P. Kœchlin, S. Potapov, Classification of soft and hard impacts-Application to aircraft crash, Nuclear Engineering and Design. 239 (2009) 613-618. doi:10.1016/j.nucengdes.2008.10.016.

[2] J.S. Wilbeck, Impact behavior of low strength projectiles, Wright-Patterson Air Force base, Dayton, OH, 1978.

[3] L.I. Boehman, A. Challita, A Model for Prediction Bird and Ice Impact Loads on Structures., Air Force Wright Aeronautical Laboratories, Wright Patterson Air Force base, Dayton, OH, 1982.

[4] S.S. Cook, Erosion by Water-Hammer, Proceedings of the Royal Society of London. Series A, Containing Papers of a Mathematical and Physical Character. 119 (1928) 481488.

[5] N.S. Corney, E.M. Minter, P. Tattershall, The rain erosion of some as-cast and pressed/stretched acrylic materials, Wright Research and Development Center, Wright Patterson Air Force base, Dayton, OH, 1989.

[6] W.F. Adler, Waterdrop impact modeling, Wear. 186 (1995) 341-351.

[7] M.H. Keegan, D.H. Nash, M.M. Stack, On erosion issues associated with the leading edge of wind turbine blades, Journal of Physics D: Applied Physics. 46 (2013) 383001.

[8] S. Zhang, K. Dam-Johansen, S. Nørkjær, P.L. Bernad, S. Kiil, Erosion of wind turbine blade coatings-Design and analysis of jet-based laboratory equipment for performance evaluation, Progress in Organic Coatings. 78 (2015) 103-115.

[9] J.E. Field, J.-J. Camus, M. Tinguely, D. Obreschkow, M. Farhat, Cavitation in impacted drops and jets and the effect on erosion damage thresholds, Wear. 290 (2012) 154-160. doi:10.1016/j.wear.2012.03.006.

[10] J.H. Brunton, High Speed Liquid Impact, Philosophical Transactions of the Royal Society of London. Series A, Mathematical and Physical Sciences. 260 (1966) 79-85. doi:10.2307/73538.

[11] F.P. Bowden, J.E. Field, The brittle fracture of solids by liquid impact, by solid impact, and by shock, Proceedings of the Royal Society of London. Series A, Mathematical and Physical Sciences. (1964) 331-352.

[12] J.P. Dear, J.E. Field, High-speed photography of surface geometry effects in liquid/solid impact, Journal of Applied Physics. 63 (1988) 1015-1021.

[13] J.E. Field, J.P. Dear, J.E. Ogren, The effects of target compliance on liquid drop impact, Journal of Applied Physics. 65 (1989) 533-540.

[14] O.G. Engel, Waterdrop collisions with solid surfaces, Journal of Research of the National Bureau of Standards. 54 (1955) 281-298.

[15] M. Rein, Phenomena of liquid drop impact on solid and liquid surfaces, Fluid Dynamics Research. 12 (1993) 61-93.

[16] J.E. Field, Stress waves, deformation and fracture caused by liquid impact, Philosophical Transactions for the Royal Society of London. Series A, Mathematical and Physical Sciences. 260 (1966) 86-93.

[17] G.S. Springer, C.-I. Yang, Analysis of Rain Erosion of Coated and Uncoated Fiber Reinforced Composite Materials, Michigan University, 1974.

[18] F.P. Bowden, J.H. Brunton, The deformation of solids by liquid impact at supersonic speeds, Proceedings of the Royal Society of London. Series A. Mathematical and Physical Sciences. 263 (1961) 433-450. 
[19] N.L. Hancox, J.H. Brunton, The Erosion of Solids by the Repeated Impact of Liquid Drops, Philosophical Transactions of the Royal Society of London. Series A, Mathematical and Physical Sciences. 260 (1966) 121-139.

[20] N.K. Bourne, J.E. Field, On the Impact and Penetration of Transparent Targets, Proceedings: Mathematical, Physical and Engineering Sciences. 455 (1999) 4169-4179. doi: $10.2307 / 53555$.

[21] N.K. Bourne, On impacting liquid jets and drops onto polymethylmethacrylate targets, Proceedings of the Royal Society a-Mathematical Physical and Engineering Sciences. 461 (2005) 1129-1145. doi:10.1098/rspa.2004.1440.

[22] W.F. Adler, J.C. Botke, T.W. James, Response of infrared-transparent materials to raindrop impacts, Air Force Materials Laboratory, Dayton, OH, 1979.

[23] C.F. Kennedy, J.E. Field, Damage threshold velocities for liquid impact, Journal of Materials Science. 35 (2000) 5331-5339. doi:10.1023/A:1004842828161.

[24] S. Van der Zwaag, J.E. Field, Liquid jet impact damage on zinc sulphide, Journal of Materials Science. 17 (1982) 2625-2636.

[25] J.E. Field, ELSI conference: invited lecture: liquid impact: theory, experiment, applications, Wear. 233 (1999) 1-12.

[26] D.A. Gorham, J.E. Field, The failure of composite materials under high-velocity liquid impact, Journal of Physics D: Applied Physics. 9 (1976) 1529-1541.

[27] N. Hancox, Erosion of carbon fiber reinforced plastic by repeated liquid impact, Wear. 23 (1973) 71-81. doi:10.1016/0043-1648(73)90042-2.

[28] M. Matthewson, D. Gohram, An investigation of the liquid impact properties of a GFRP radome material, Journal of Materials Science. 16 (1981) 1616-1626.

[29] M. Mani, S. Mandre, M.P. Brenner, Events before droplet splashing on a solid surface, Journal of Fluid Mechanics. 647 (2010) 163-185. doi:10.1017/S0022112009993594.

[30] S.T. Thoroddsen, T.G. Etoh, K. Takehara, N. Ootsuka, Y. Hatsuki, The air bubble entrapped under a drop impacting on a solid surface, Journal of Fluid Mechanics. 545 (2005) 203-212. doi:10.1017/S0022112005006919.

[31] S.T. Thoroddsen, T.G. Etoh, K. Takehara, Air entrapment under an impacting drop, Journal of Fluid Mechanics. 478 (2003) 125-134. doi:10.1017/S0022112002003427.

[32] J. Thorpe, Fatalities and destroyed civil aircraft due to bird strikes, 1912-2002, in: International Bird Strike Committee, 26th Meeting. Warsaw, Poland, 2003.

[33] R. Hedayati, S. Ziaei-Rad, A. Eyvazian, A.M. Hamouda, Bird strike analysis on a typical helicopter windshield with different lay-ups, Journal of Mechanical Science and Technology. 28 (2014) 1381-1392.

[34] K.A. Avrenli, B.J. Dempsey, Statistical analysis of aircraft-bird strikes resulting in engine failure 2, in: Transportation Research Board 93rd Annual Meeting, 2014.

[35] W.R. Jansen, Analysis of Shock-Absorbing Concepts for Bird-Proof Windshields of Advanced Air Force Vehicles, Air Force Wright Aeronautical Laboratories, Dayton, $\mathrm{OH}$, 1976.

[36] P.P. Marra, C.J. Dove, R. Dolbeer, N.F. Dahlan, M. Heacker, J.F. Whatton, et al., Migratory Canada geese cause crash of US Airways Flight 1549, Frontiers in Ecology and the Environment. 7 (2009) 297-301. doi:10.1890/090066.

[37] E. Fernandez-Juricic, J. Gaffney, B. Blackwell, P. Baumhardt, Bird strikes and aircraft fuselage color: a correlational study, Human - Wildlife Interactions. 5 (2011) 224 - 234. 
[38] B.F. Blackwell, G.E. Bernhardt, Efficacy of aircraft landing lights in stimulating avoidance behavior in birds, Journal of Wildlife Management. 68 (2004) 725-732. doi:10.2193/0022-541X(2004)068[0725:EOALLI]2.0.CO;2.

[39] J. Barber, H.R. Taylor, J.S. Wilbeck, Characterization of Bird Impacts on a Rigid Plate: Part 1, Wright-Patterson Air Force base, Dayton, OH, 1975.

[40] J.P. Barber, P.F. Fry, J.M. Klyce, H.R. Taylor, Impact of soft bodies on jet engine fan blades, Wright-Patterson Air Force base, Dayton, OH, 1977.

[41] J.P. Barber, H.R. Taylor, J.S. Wilbeck, Bird impact forces and pressures on rigid and compliant targets, Wright-Patterson Air Force base, Dayton, OH, 1978.

[42] A. Challita, J.P. Barber, The scaling of bird impact loads, Air Force Wright Aeronautical Laboratories, Wright Patterson Air Force base, Dayton, OH, 1979.

[43] A. Challita, B.S. West, Effects of Bird Orientation at Impact on Load Profile and Damage Level, Wright-Patterson Air Force base, Dayton, OH, 1980.

[44] A. Challita, Validation of a Bird Substitute for Development and Qualification of Aircraft Transparenciles, Wright-Patterson Air Force base, Dayton, OH, 1980.

[45] M. Anghileri, A. Milanese, G. Moretti, L. Castelletti, Preliminary investigation on the feasibility of a bird surrogate for full-scale bird impact test, in: ICAS 2012 CD-ROM PROCEEDINGS, Brisbane, Australia, 2012.

[46] M.A. Lavoie, A. Gakwaya, M.N. Ensan, D.G. Zimcik, D. Nandlall, Bird's substitute tests results and evaluation of available numerical methods, International Journal of Impact Engineering. 36 (2009) 1276-1287. doi:10.1016/j.ijimpeng.2009.03.009.

[47] A.N. Shupikov, S.V. Ugrimov, N.V. Smetankina, V.G. Yareshchenko, G.G. Onhirsky, V.P. Ukolov, et al., Bird Dummy for Investigating the Bird-Strike Resistance of Aircraft Components, Journal of Aircraft. 50 (2012) 817-826.

[48] J.P. Hou, C. Ruiz, Soft body impact on laminated composite materials, Composites Part A: Applied Science and Manufacturing. 38 (2007) 505-515. doi:10.1016/j.compositesa.2006.02.018.

[49] M. Guida, F. Marulo, M. Meo, A. Grimaldi, G. Olivares, SPH - Lagrangian study of bird impact on leading edge wing, Composite Structures. 93 (2011) 1060-1071. doi:10.1016/j.compstruct.2010.10.001.

[50] M. Guida, F. Marulo, M. Meo, S. Russo, Certification by birdstrike analysis on C27J fullscale ribless composite leading edge, International Journal of Impact Engineering. 54 (2013) 105-113. doi:10.1016/j.ijimpeng.2012.10.002.

[51] M.V. Donadon, M.A. Arbelo, S.F.M. de Almeida, M. Actis, A.J. Pantanella, Bird strike modeling in composite stiffened panels, in: Proceedings of PACAM XI, , Foz do Iguaçu, PR, Brazil, 2009.

[52] A.G. Hanssen, Y. Girard, L. Olovsson, T. Berstad, M. Langseth, A numerical model for bird strike of aluminium foam-based sandwich panels, International Journal of Impact Engineering. 32 (2006) 1127-1144. doi:10.1016/j.ijimpeng.2004.09.004.

[53] M. Kim, A. Zammit, A. Siddens, J. Bayandor, An Extensive crashworthiness methodology for advanced propulsion systems, Part I: Soft impact damage assessment of composite fan stage assemblies, in: Orlando, Florida, 2011. http://arc.aiaa.org/doi/pdf/10.2514/6.2011980 (accessed December 4, 2014).

[54] C.-H. Tho, M.R. Smith, Accurate Bird Strike Simulation Methodology for BA609 Tiltrotor, Journal of the American Helicopter Society. 56 (2011). doi:10.4050/JAHS.56.012007. 
[55] M. Selezneva, P. Stone, T. Moffat, K. Behdinan, C. Poon, Modeling bird impact on a rotating fan: the influence of bird parameters, Aerospace Journal. (2012) 4.

[56] P.G. Tait, Report on some of the physical properties of fresh-water and of sea-water, Physical Chemistry. 2 (1888) 1-71.

[57] S. Abrate, Hull Slamming, Applied Mechanics Reviews. 64 (2011). doi:10.1115/1.4023571.

[58] R. Panciroli, S. Abrate, G. Minak, A. Zucchelli, Hydroelasticity in water-entry problems: Comparison between experimental and SPH results, Composite Structures. 94 (2012) 532539. doi:10.1016/j.compstruct.2011.08.016.

[59] R. Panciroli, S. Abrate, G. Minak, Dynamic response of flexible wedges entering the water, Composite Structures. 99 (2013) 163-171.

[60] F.D. Murnaghan, The compressibility of media under extreme pressures, Proceedings of the National Academy of Sciences of the United States of America. 30 (1944) 244-247.

[61] G. Yupu, Z. Zhenhua, C. Wei, G. Deping, Foreign object damage to fan rotor blades of aeroengine part II: numerical simulation of bird impact, Chinese Journal of Aeronautics. 21 (2008) 328-334.

[62] R.H. Mao, S.A. Meguid, T.Y. Ng, Transient three dimensional finite element analysis of a bird striking a fan blade, International Journal of Mechanics and Materials in Design. 4 (2008) 79-96. doi:10.1007/s10999-008-9067-1.

[63] R.H. Mao, S.A. Meguid, T.Y. Ng, Effects of incidence angle in bird strike on integrity of aero-engine fan blade, International Journal of Crashworthiness. 14 (2009) 295-308. doi:10.1080/13588260802671415.

[64] R.A. Brockman, T.W. Held, Explicit finite element method for transparency impact analysis, Wright Laboratory, Wright Patterson Air Force base, Dayton, OH, 1991.

[65] S.A. Meguid, R.H. Mao, T.Y. Ng, FE analysis of geometry effects of an artificial bird striking an aeroengine fan blade, International Journal of Impact Engineering. 35 (2008) 487-498. doi:10.1016/j.ijimpeng.2007.04.008.

[66] F. Stoll, R.A. Brockman, Assessment of Mathematical Bird Models for Bird Impact Analysis with an Explicit Finite Element Code, in: Proceedings of the Conference on Aerospace Transparent Materials and Enclosures, Wright Laboratory, Wright Patterson Air Force base, Dayton, OH, 1994: pp. 791-812.

[67] F.S. Wang, Z.F. Yue, W.Z. Yan, Factors study influencing on numerical simulation of aircraft windshield against bird strike, Shock and Vibration. 18 (2011) 407-424. doi:10.3233/SAV-2010-0522.

[68] J. Donea, A. Huerta, J.-P. Ponthot, A. Rodríguez-Ferran, Arbitrary Lagrangian-Eulerian Methods, in: Encyclopedia of Computational Mechanics, John Wiley \& Sons, Ltd, 2004. http://onlinelibrary.wiley.com/doi/10.1002/0470091355.ecm009/abstract (accessed March $5,2015)$.

[69] T. Belytschko, T. Rabczuk, A. Huerta, S. Fernández-Méndez, Meshfree Methods, in: Encyclopedia of Computational Mechanics, John Wiley \& Sons, Ltd, 2004. http://onlinelibrary.wiley.com/doi/10.1002/0470091355.ecm005/abstract (accessed March 5, 2015).

[70] I. Smojver, D. Ivančević, Numerical simulation of bird strike damage prediction in airplane flap structure, Composite Structures. 92 (2010) 2016-2026. doi:10.1016/j.compstruct.2009.12.006. 
[71] Y.N. Shmotin, P.V. Chupin, D.V. Gabov, A.A. Ryabov, V.I. Romanov, S.S. Kukanov, et al., Bird strike analysis of aircraft engine fan, in: Proceedings of the 7th European LSDYNA Users Conference, Salzburg, Austria, May 14Ā19, LSTC, Livermore, CA, 2009.

[72] I. Smojver, D. Ivancevic, Numerical Modelling of Impact Damage in Multi-Material Airplane Structure, in: Edinburgh, UK, 2009.

[73] J.L. Yang, X.J. Cai, C.H. Wu, Experimental and FEM study of windshield subjected to high speed bird impact, Acta Mechanica Sinica. 19 (2003) 543-550.

[74] U.A. Dar, W. Zhang, Y. Xu, FE Analysis of Dynamic Response of Aircraft Windshield against Bird Impact, International Journal of Aerospace Engineering. 2013 (2013) 1-11.

[75] Z. Jianyong, Z. Xiaoyu, W. Mengling, Numerical simulation of bird impact on composite aerodynamic brake wing of high-speed train, Proceedings of the Institution of Mechanical Engineers, Part F: Journal of Rail and Rapid Transit. (2013) 0954409713508109. doi:10.1177/0954409713508109.

[76] R.L. Azevedo, M. Alves, Numerical simulation of bird strike impact against balanced fiberglass/epoxy composite plates, in: Proceedings of the 19th International Congress of Mechanical Engineering, Brasilia, Brazil, 2007.

[77] N. Lakshman, R. Raj, Y. Mukkamala, Bird strike analysis of jet engine fan blade, in: Aerospace Conference, 2014 IEEE, IEEE, 2014: pp. 1-7. http://ieeexplore.ieee.org/xpls/abs_all.jsp?arnumber=6836249 (accessed December 18, 2014).

[78] A.A. Ryabov, V.I. Romanov, S.S. Kukanov, Y. Shmotin, P. Chupin, N.P.O. Saturn, Fan blade bird strike analysis using Lagrangian, SPH and ALE approaches, in: 6th European LS-DYNA Users Conference, 2007. http://www.dynalook.com/european-conf-2007/fanblade-bird-strike-analysis-using-lagrangian.pdf (accessed June 8, 2014).

[79] S.C. McCallum, C. Constantinou, S. McCallum, The influence of bird-shape in bird-strike analysis, in: Proc. 5th European LS-DYNA Users Conference, Birmingham, UK, 2005.

[80] S. Wang, Z. Feng, F. Wang, Z. Yue, Dynamic response analysis of bird strike on aircraft windshield based on damage-modified nonlinear viscoelastic constitutive relation, Chinese Journal of Aeronautics. 20 (2007) 511-517.

[81] J. Cheng, W.K. Binienda, Simulation of soft projectiles impacting composite targets using an arbitrary Lagrangian-Eulerian Formulation, Journal of Aircraft. 43 (2006) 1726-1731.

[82] A. Zammit, M. Kim, J. Bayandor, Bird-strike damage tolerance analysis of composite turbofan engines, in: ICAS 2010, 27th International Congress of the Aeronautical Sciences, 2010. http://www.icas.org/ICAS_ARCHIVE/ICAS2010/PAPERS/410.PDF (accessed February 1, 2015).

[83] S.A. Howard, J.T. Hammer, K.S. Carney, J.M. Pereira, Jet Engine Bird Ingestion Simulations: Comparison of Rotating to Non-Rotating Fan Blades, in: ASME Turbo Expo 2013: Turbine Technical Conference and Exposition, American Society of Mechanical Engineers, 2013: pp. V002T01A032-V002T01A032.

[84] I. Smojver, D. Ivancevic, Advanced modelling of bird strike on high lift devices using hybrid Eulerian-Lagrangian formulation, Aerospace Science and Technology. 23 (2012) 224-232. doi:10.1016/j.ast.2011.07.010.

[85] D. Ivančević, I. Smojver, Hybrid approach in bird strike damage prediction on aeronautical composite structures, Composite Structures. 94 (2011) 15-23. doi:10.1016/j.compstruct.2011.07.028. 
[86] I. Smojver, D. Ivančević, Bird strike damage analysis in aircraft structures using Abaqus/Explicit and coupled Eulerian Lagrangian approach, Composites Science and Technology. 71 (2011) 489-498. doi:10.1016/j.compscitech.2010.12.024.

[87] S. Heimbs, Bird strike simulations on composite aircraft structures, in: 2011 SIMULIA Customer Conference. Barcelona, Spain, 2011: pp. 73-86.

[88] I. Smojver, D. Ivancevic, Bird impact at aircraft structure - Damage analysis using Coupled Euler Lagrangian Approach, IOP Conference Series: Materials Science and Engineering. 10 (2010) 012050. doi:10.1088/1757-899X/10/1/012050.

[89] S. Heimbs, T. Bergmann, High-Velocity Impact Behaviour of Prestressed Composite Plates under Bird Strike Loading, International Journal of Aerospace Engineering. 2012 (2012) 1-11. doi:10.1155/2012/372167.

[90] R. Jain, K. Ramachandra, Bird impact analysis of pre-stressed fan blades using explicit finite element code, in: Proceedings of the International Gas Turbine Congress, Tokyo, Japan, 2003.

[91] M.A. Lavoie, A. Gakwaya, M.N. Ensan, D.G. Zimcik, Validation of available approaches for numerical bird strike modeling tools, International Review of Mechanical Engineering. 1 (2007) 225-231.

[92] M.A. Lavoie, A. Gakwaya, M.N. Ensan, D.G. Zimcik, Review of existing numerical methods and validation procedure available for bird strike modelling, in: Miami, FL, USA, 2007: pp. 111-118.

[93] S.-T. Jenq, F.-B. Hsiao, I.C. Lin, D.G. Zimcik, M.N. Ensan, Simulation of a rigid plate hit by a cylindrical hemi-spherical tip-ended soft impactor, Computational Materials Science. 39 (2007) 518-526.

[94] S. Heimbs, Computational methods for bird strike simulations: A review, Computers \& Structures. 89 (2011) 2093-2112. doi:10.1016/j.compstruc.2011.08.007.

[95] J. Liu, Y. Li, X. Gao, Bird strike on a flat plate: Experiments and numerical simulations, International Journal of Impact Engineering. 70 (2014) 21-37. doi:10.1016/j.ijimpeng.2014.03.006.

[96] M. Ugrčić, Application of the hydrodynamic theory and the finite element method in the analysis of bird strike in a flat barrier, Scientific Technical Review. 62 (2012) 28-37.

[97] M.A. McCarthy, J.R. Xiao, C.T. McCarthy, A. Kamoulakos, J. Ramos, J.P. Gallard, et al., Modelling bird impacts on an aircraft wing - Part 2: Modelling the impact with an SPH bird model, International Journal of Crashworthiness. 10 (2005) 51-59. doi:10.1533/ijcr.2005.0325.

[98] J. Liu, Y. Li, X. Gao, X. Yu, A numerical model for bird strike on sidewall structure of an aircraft nose, Chinese Journal of Aeronautics. 27 (2014) 542-549. doi:10.1016/j.cja.2014.04.019.

[99] R. Vignjevic, M. Orłowski, T. De Vuyst, J.C. Campbell, A parametric study of bird strike on engine blades, International Journal of Impact Engineering. 60 (2013) 44-57. doi:10.1016/j.ijimpeng.2013.04.003.

[100] B.E. Washburn, P.J. Cisar, T.L. DEvault, Wildlife strikes with military rotary-wing aircraft during flight operations within the United States, Wildlife Society Bulletin. (2014). doi:DOI: 10.1002/wsb.409.

[101] Liu Fu, Zhang Jiazhen, Hu Zhongmin, Zhang Mingyi, Numerical Analysis of Bird Impact on a GLARE Plate, Polymers \& Polymer Composites. 21 (2013) 587-592. 
[102] M. Anghileri, L.-M. Castelletti, F. Invernizzi, M. Mascheroni, Birdstrike onto the composite intake of a turbofan engine, in: Proc. 5th European LS-DYNA Users Conference, Birmingham, UK, 2005.

[103] A. Siddens, J. Bayandor, Multidisciplinary impact damage prognosis methodology for hybrid structural propulsion systems, Computers \& Structures. 122 (2013) 178-191.

[104] A. Grimaldi, A. Sollo, M. Guida, F. Marulo, Parametric study of a SPH high velocity impact analysis - A birdstrike windshield application, Composite Structures. 96 (2013) 616-630. doi:10.1016/j.compstruct.2012.09.037.

[105] M. Guida, A. Grimaldi, F. Marulo, M. Meo, G. Olivares, Bird impact on leading edge wing with SPH formulation, in: 17th International Conference on Composite Materials, ICCM-17, Edinburgh, UK, 2009. http://iccmcentral.org/Proceedings/ICCM17proceedings/Themes/TSAI/T1.3\%20Guida.pdf (accessed September 23, 2014).

[106] R.L. Azevedo, M. Alves, Numerical simulation of soft-body impact on GFRP laminate composites: mixed SPH-FE and pure SPH approaches, in: Mechanics of Solids in Brazil, 2009: pp. 15-30. http://www.abcm.org.br/pt/wp-content/symposiumseries/SSSM_Vol2/Contents/SSSM_02.pdf (accessed January 19, 2015).

[107] P.T. Bharath, Investigation of Bird Hit on Preloaded Composite Stiffened Panels, Journal of Mechanical Engineering. 2 (2014) 75-83.

[108] J. Liu, Y. Li, Numerical simulation of a rotary engine primary compressor impacted by bird, Chinese Journal of Aeronautics. 26 (2013) 926-934. doi:10.1016/j.cja.2013.06.006.

[109] L.-M. Castelletti, M. Anghileri, Toward a methodology for the design of bird-proof intakes made with composite materials, in: Proceedings of the 25th Congress of the International Council of the Aeronautical Sciences, Hamburg, Germany, 2006.

[110] M. Anghileri, L.M.L. Castelletti, V. Mazza, Birdstrike: approaches to the analysis of impacts with penetration, in: M. Alves, N. Jones (Eds.), Impact Loading of Lightweight Structures, 2005: pp. 63-74.

[111] M. Anghileri, L.-M.L. Castelletti, D. Molinelli, F. Motta, A strategy to design bird-proof spinners, in: 25th Congress of the Proceedings of the 7th European LS-DYNA Users Conference, Salzburg, Austria, 2009.

[112] L.-M.L. Castelletti, M. Anghileri, Birdstrike onto structures in rotational motion, in: Proceedings of the 26th International Congress of the Aeronautical Sciences, ICAS, Anchorage, Alaska, 2008: pp. 14-19.

[113] S. Georgiadis, A.J. Gunnion, R.S. Thomson, B.K. Cartwright, Bird-strike simulation for certification of the Boeing 787 composite moveable trailing edge, Composite Structures. 86 (2008) 258-268. doi:10.1016/j.compstruct.2008.03.025.

[114] A.J. Siddens, J. Bayandor, Detailed post-soft impact progressive damage analysis for a hybrid structure jet engine, in: , Optimage Ltd., Brisbane, Australia, Brisbane, Australia, 2012.

[115] Y. Duplessis Kergomard, F. Dau, Y. Iordanoff, Implementation of a Discrete Element Method for the space-time modeling of loading in the case of a soft shock: qualitative approach, Journal of Computations \& Modelling. 1 (2011) 39-72.

[116] C. Zeng, X. Jiang, X. Chai, T. Shi, TC4 Hollow Fan Blade Structural Optimization Based on Bird-Strike Analysis, Procedia Engineering. (2014). 
[117] R. Hedayati, S. Ziaei-Rad, A new bird model and the effect of bird geometry in impacts from various orientations, Aerospace Science and Technology. 28 (2013) 9-20. doi:10.1016/j.ast.2012.09.002.

[118] A.F. Johnson, M. Holzapfel, Modelling soft body impact on composite structures, Composite Structures. 61 (2003) 103-113. doi:10.1016/S0263-8223(03)00033-3.

[119] A. Airoldi, B. Cacchione, Modelling of impact forces and pressures in Lagrangian bird strike analyses, International Journal of Impact Engineering. 32 (2006) 1651-1677. doi:10.1016/j.ijimpeng.2005.04.011.

[120] B.S. West, R.A. Brockman, Evaluation of Bird Load Models for Dynamic Analysis of Aircraft Transparencies., DTIC Document, 1980.

[121] M. Rosenblatt, G.E. Eggum, L.A. DeAngelo, K.N. Kreyenhagen, Numerical Analyses of Soft Body Impacts on Rigid and Deformable Targets., Wright-Patterson Air Force base, Dayton, OH, 1976.

[122] S. Abrate, Impact on composite structures, Cambridge University Press, 2005.

[123] J. Liu, Y. Li, Z. Zhang, Dynamic response of bird strike on 7075 Aluminium plate, in: 9th International Conference on Fracture \& Strength of Solids, Jeju , Korea, 2013.

[124] J. Liu, Y. Li, X. Shi, W. Wang, Dynamic Response of Bird Strike on Aluminum Honeycomb-Based Sandwich Panels, Journal of Aerospace Engineering. 27 (2014) 520528. doi:10.1061/(ASCE)AS.1943-5525.0000280.

[125] E.C. Cleary, R.A. Dolbeer, S.E. Wright, Wildlife strikes to civil aircraft in the United States 1990-2005, Federal Aviation Administration, 2006. http://digitalcommons.unl.edu/birdstrikeother/7/ (accessed January 22, 2015).

[126] J. Thorpe, The implications of recent serious bird strike accidents and multiple engine ingestions, in: International Workshop on New Technologies for Bird Strike Prevention, Boston, US, 1997. http://worldbirdstrike.com/IBSC/Slovakia/IBSC24\%20WP03.pdf (accessed January 22, 2015).

[127] T.L. Alge, J.T. Moehring, Modern Transport Engine Experience with Environmental Ingestion Effects, in: AGARD CONFERENCE PROCEEDINGS AGARD CP 558, AGARD, 1994: pp. 9-9.

[128] S.K. Sinha, K.E. Turner, N. Jain, Dynamic Loading on Turbofan Blades Due to BirdStrike, Journal of Engineering for Gas Turbines and Power-Transactions of the Asme. 133 (2011). doi:10.1115/1.4004126.

[129] A. Siddens, J. Bayandor, An Extensive Crashworthiness Methodology for Advanced Propulsion Systems, Part II: Damage and Vibration Instability Analysis of Jet Engine Forward Sections, in: Proceedings of the 49th AIAA Aerospace Sciences Meeting Including the New Horizons Forum and Aerospace Exposition, Orlando, Florida, 2011.

[130] A.J. Siddens, J. Bayandor, F. Abdi, Coupled micromechanics-finite element progressive failure dynamic analysis approach: F-16 canopy case study, in: Brisbane, Australia, 2012.

[131] R. Doubrava, V. Strnad, Bird strike analyses on the parts of aircraft structure, in: Proceedings of the 27th Congress of the International Council of the Aeronautical Sciences, Nice, France, 2010.

[132] R. McCarty, Evaluation of the Impact Computer Program as a Linear Design Tool for Bird-Resistant Aircraft Transparencies, Wright-Patterson Air Force base, Dayton, OH, 1980.

[133] J. Wang, Y. Xu, W. Zhang, Finite element simulation of PMMA aircraft windshield against bird strike by using a rate and temperature dependent nonlinear viscoelastic 
constitutive model, Composite Structures. 108 (2014) 21-30.

doi:10.1016/j.compstruct.2013.09.001.

[134] F.S. Wang, Z.F. Yue, Numerical simulation of damage and failure in aircraft windshield structure against bird strike, Materials \& Design. 31 (2010) 687-695. doi:10.1016/j.matdes.2009.08.029.

[135] F. Marulo, M. Guida, Design criteria for birdstrike damage on windshield, Advances in Aircraft and Spacecraft Science. 1 (2014) 233-251. doi:10.12989/aas.2014.1.2.233.

[136] M. Guida, A. Grimaldi, F. Marulo, A. Sollo, FE study of windshield subjected to high speed bird impact, in: Proceedings of the 26th International Congress of the Aeronautical Sciences (ICAS'08), Anchorage, Alaska, 2008.

[137] P.A. Hooper, B.R.K. Blackman, J.P. Dear, The mechanical behaviour of poly(vinyl butyral) at different strain magnitudes and strain rates, Journal of Materials Science. 47 (2012) 3564-3576. doi:10.1007/s10853-011-6202-4.

[138] M. Froli, L. Lani, Adhesion, creep and relaxation properties of PVB in laminated safety glass, Glass Performance Days, Tampere (Finland). (2011).

[139] S.B. Bati, G. Ranocchiai, C. Reale, L. Rovero, Time-dependent behavior of laminated glass, Journal of Materials in Civil Engineering. 22 (2009) 389-396.

[140] P.. Du Bois, S. Kolling, W. Fassnacht, Modelling of safety glass for crash simulation, Computational Materials Science. 28 (2003) 675-683. doi:10.1016/j.commatsci.2003.08.023.

[141] A.V. Duser, A. Jagota, S.J. Bennison, Analysis of glass/polyvinyl butyral laminates subjected to uniform pressure, Journal of Engineering Mechanics. 125 (1999) 435-442.

[142] G.O. Antoine, R.C. Batra, Constitutive Relations and Parameter Estimation for Finite Deformations of Viscoelastic Adhesives, Journal of Applied Mechanics. 82 (2015) 021001.

[143] A. Deb, K. Vijayaraju, T.C.S. Reddy, Combined Applications of Test and CAE for Assessing Performance of Aircraft Windshield-Like Structures under Bird Impacts, International Journal of Vehicle Structures \& Systems (IJVSS). 1 (2009) 30-38. doi:10.4273/ijvss.1.1-3.04.

[144] T. Belytschko, E. Privitzer, W. Mindle, T. Wicks, Computer Simulation of Canopy-Pilot Response to Bird-Strike., Wright-Patterson Air Force base, Dayton, OH, 1979.

[145] M. Alves, C. Chaves, R.S. Birch, Impact on aircraft, in: Proceedings of the XVII Brazilian Congress of Mechanical Engineering, 2003. http://www.abcm.org.br/pt/wpcontent/anais/cobem/2003/html/pdf/COB03-1593.pdf (accessed December 7, 2014).

[146] A.F. Johnson, M. Holzapfel, Numerical prediction of damage in composite structures from soft body impacts, Journal of Materials Science. 41 (2006) 6622-6630. doi:10.1007/s10853-006-0201-X.

[147] J. Bayandor, A. Johnson, R.S. Thomson, M. Joosten, Impact damage modelling of composite aerospace structures subject to bird-strike, in: 25th International Congress of the Aeronautical Sciences, 2006.

[148] M.A. McCarthy, J.R. Xiao, N. Petrinic, A. Kamoulakos, V. Melito, Modelling bird impacts on an aircraft wing - Part 1: Material modelling of the fibre metal laminate leading edge material with continuum damage mechanics, International Journal of Crashworthiness. 10 (2005) 41-49. doi:10.1533/ijcr.2005.0324. 
[149] M.A. McCarthy, J.R. Xiao, N. Petrinic, A. Kamoulakos, V. Melito, Modelling of bird strike on an aircraft wing leading edge made from fibre metal laminates-Part 1: Material modelling, Applied Composite Materials. 11 (2004) 295-315.

[150] M.A. McCarthy, J.R. Xiao, C.T. McCarthy, A. Kamoulakos, J. Ramos, J.P. Gallard, et al., Modelling of bird strike on an aircraft wing leading edge made from fibre metal laminates-part 2: modelling of impact with SPH bird model, Applied Composite Materials. 11 (2004) 317-340.

[151] T. Kermanidis, G. Labeas, M. Sunaric, A.F. Johnson, M. Holzapfel, Bird strike simulation on a novel composite leading edge design, International Journal of Crashworthiness. 11 (2006) 189-201. doi:10.1533/ijcr.2005.0389.

[152] T. Kermanidis, G. Labeas, M. Sunaric, L. Ubels, Development and Validation of a Novel Bird Strike Resistant Composite Leading Edge Structure, Applied Composite Materials. 12 (2005) 327-353. doi:10.1007/s10443-005-3441-z.

[153] L.C. Ubels, J.F.M. Wiggenraad, Increasing the survivability of helicopter accidents over water, in: 1st European Survivability Workshop, Cologne-Wahn, Germany, Citeseer, 2002.

[154] R. Poola, Bird Strike Impact Analysis of Vertical Stabilizer Structure Using Abaqus/Explicit, in: ITC Gardenia, Bengaluru India, 2011.

[155] M. Guida, F. Marulo, M. Meo, M. Riccio, Analysis of Bird Impact on a Composite Tailplane Leading Edge, Applied Composite Materials. 15 (2008) 241-257. doi:10.1007/s10443-008-9070-6.

[156] R.K. Souter, J.B. Emerson, Summary of available hail literature and the effect of hail on aircraft in flight, National Advisory Committee for Aeronautics, Langley Field, VA, 1952.

[157] I.I. Gringorten, Hailstone extremes for design, Air Force Systems Command, Bedford, MA, 1971.

[158] A. Askari, K. Nelson, O. Weckner, J. Xu, S. Silling, Hail Impact Characteristics of a Hybrid Material by Advanced Analysis Techniques and Testing, Journal of Aerospace Engineering. 24 (2011) 210-217. doi:10.1061/(ASCE)AS.1943-5525.0000034.

[159] E.M. Schulson, The brittle failure of ice under compression, The Journal of Physical Chemistry B. 101 (1997) 6254-6258.

[160] E.M. Schulson, The structure and mechanical behavior of ice, JOM. 51 (1999) 21-27.

[161] J.D. Tippmann, H. Kim, J.D. Rhymer, Experimentally validated strain rate dependent material model for spherical ice impact simulation, International Journal of Impact Engineering. 57 (2013) 43-54. doi:10.1016/j.ijimpeng.2013.01.013.

[162] A. Combescure, Y. Chuzel-Marmot, J. Fabis, Experimental study of high-velocity impact and fracture of ice, International Journal of Solids and Structures. 48 (2011) 2779-2790.

[163] J.M. Pereira, S.A. Padula, D.M. Revilock, M.E. Melis, Forces generated by high velocity impact of ice on a rigid structure, NASA Glenn Research Center, Cleveland, OH, 2006.

[164] E.M. Schulson, Brittle failure of ice, Engineering Fracture Mechanics. 68 (2001) 18391887.

[165] R. Ortiz, E. Deletombe, Y. Chuzel-Marmot, Assessment of damage model and strain rate effects on the fragile stress/strain response of ice material, International Journal of Impact Engineering. 76 (2015) 126-138. doi:10.1016/j.ijimpeng.2014.09.011.

[166] Y. Chuzel, A. Combescure, M. Nucci, R. Ortiz, Y. Perrin, Development of hail material model for high speed impacts on aircraft engine, in: Detroit, MI, 2010. 
[167] H.A. Khoo, T.M. Hrudey, Constitutive model for ice, Journal of Engineering Mechanics. 118 (1992) 259-279.

[168] H.A. Khoo, T.M. Hrudey, Finite-element simulation of ice-sheet indentation, Journal of Engineering Mechanics. 120 (1994) 1322-1342.

[169] D.G. Karr, K. Choi, A three-dimensional constitutive damage model for polycrystalline ice, Mechanics of Materials. 8 (1989) 55-66.

[170] P. Zamankhan, Simulations of collision of ice particles, Communications in Nonlinear Science and Numerical Simulation. 15 (2010) 1538-1552. doi:10.1016/j.cnsns.2009.06.029.

[171] J.F. Nye, The flow of glaciers and ice-sheets as a problem in plasticity, Proceedings of the Royal Society of London. Series A. Mathematical and Physical Sciences. 207 (1951) 554 572.

[172] J.F. Nye, The Distribution of Stress and Velocity in Glaciers and Ice-Sheets, Proceedings of the Royal Society of London. Series A, Mathematical and Physical Sciences. 239 (1957) 113-133.

[173] S. Abrate, Criteria for yielding or failure of cellular materials, Journal of Sandwich Structures and Materials. 10 (2008) 5-51.

[174] J. Pernas-Sánchez, D.A. Pedroche, D. Varas, J. López-Puente, R. Zaera, Numerical modeling of ice behavior under high velocity impacts, International Journal of Solids and Structures. 49 (2012) 1919-1927. doi:10.1016/j.ijsolstr.2012.03.038.

[175] K.S. Carney, D.J. Benson, P. DuBois, R. Lee, A phenomenological high strain rate model with failure for ice, International Journal of Solids and Structures. 43 (2006) 7820-7839.

[176] M. Anghileri, L.M.L. Castelletti, F. Invernizzi, M. Mascheroni, A survey of numerical models for hail impact analysis using explicit finite element codes, International Journal of Impact Engineering. 31 (2005) 929-944.

[177] D. Delsart, J. Fabis, A. Vagnot, Ice impacts modelling using Smooth Particle Hydrodynamic method, in: Proceedings of the 4th European Conference for Aerospace Sciences (EUCASS 2011), St Petersburg, Russia, 2011.

[178] M.H. Keegan, D. Nash, M. Stack, Numerical modelling of hailstone impact on the leading edge of a wind turbine blade, EWEA Annual Wind Energy Event 2013. (2013). http://strathprints.strath.ac.uk/42830/ (accessed December 9, 2014).

[179] M.-A. Lavoie, M. Nejad Ensan, A. Gakwaya, Development of an efficient numerical model for hail impact simulation based on experimental data obtained from pressure sensitive film, Mechanics Research Communications. 38 (2011) 72-76. doi:10.1016/j.mechrescom.2010.07.014.

[180] M.-A. Lavoie, A. Gakwaya, M.J. Richard, D. Nandlall, M.N. Ensan, D.G. Zimcik, Numerical and experimental modeling for bird and hail impacts on aircraft structure, in: $T$. Proulx (Ed.), Structural Dynamics, Volume 3, Springer New York, 2011: pp. 1403-1410.

[181] I.I. McNaughtan, S.W. Chisman, A study of hail impact at high speed on light alloy plates, DTIC Document, 1940.

[182] R.J. Hayduk, R.G. Thomson, An improved analytical treatment of the denting of thin sheets by hail, NASA Langley Research Center, Hampton, VA, 1971.

[183] M. Sadighi, T. Pärnänen, R.C. Alderliesten, M. Sayeaftabi, R. Benedictus, Experimental and numerical investigation of metal type and thickness effects on the impact resistance of fiber metal laminates, Applied Composite Materials. 19 (2012) 545-559. 
[184] J.G. Carrillo, W.J. Cantwell, Scaling effects in the low velocity impact response of fibermetal laminates, Journal of Reinforced Plastics and Composites. (2008).

[185] N. Tsartsaris, M. Meo, F. Dolce, U. Polimeno, M. Guida, F. Marulo, Low-velocity impact behavior of fiber metal laminates, Journal of Composite Materials. (2011) 0021998310376108.

[186] R. Starikov, Assessment of impact response of fiber metal laminates, International Journal of Impact Engineering. 59 (2013) 38-45. doi:10.1016/j.ijimpeng.2013.02.008.

[187] S. Abrate, Impact engineering of composite structures, Springer, 2011.

[188] S. Abrate, Localized impact on sandwich structures with laminated facings, Applied Mechanics Reviews. 50 (1997) 69.

[189] G.J. Appleby-Thomas, P.J. Hazell, G. Dahini, On the response of two commerciallyimportant CFRP structures to multiple ice impacts, Composite Structures. 93 (2011) 2619-2627. doi:10.1016/j.compstruct.2011.04.029.

[190] M. Mahinfalah, R.A. Skordahl, The effects of hail damage on the fatigue strength of a graphite/epoxy composite laminate, Composite Structures. 42 (1998) 101-106.

[191] M. Das, E. Oterkus, E. Madenci, H. Razi, Residual strength of sandwich panels with hail damage, Composite Structures. 88 (2009) 403-412.

[192] H. Kim, D.A. Welch, K.T. Kedward, Experimental investigation of high velocity ice impacts on woven carbon/epoxy composite panels, Composites Part A: Applied Science and Manufacturing. 34 (2003) 25-41.

[193] L.E. Asp, R. Juntikka, High velocity impact on NCF reinforced composites, Composites Science and Technology. 69 (2009) 1478-1482. doi:10.1016/j.compscitech.2008.05.027.

[194] J. Rhymer, H. Kim, D. Roach, The damage resistance of quasi-isotropic carbon/epoxy composite tape laminates impacted by high velocity ice, Composites Part A: Applied Science and Manufacturing. 43 (2012) 1134-1144. doi:10.1016/j.compositesa.2012.02.017. 
Table 1: Coefficients in polynomial equation of state for birds different porosity levels Selezneva [55]

\begin{tabular}{|l|l|l|l|}
\hline & $0 \%$ porosity & $10 \%$ porosity & $15 \%$ porosity \\
\hline $\mathrm{C}_{1}$ & 2060 & 28 & 6.9 \\
\hline $\mathrm{C}_{2}$ & 6160 & -85 & -3180 \\
\hline $\mathrm{C}_{3}$ & 10300 & 35000 & 31000 \\
\hline
\end{tabular}

\section{List of figures}

Figure 1: Interaction of a soft impactor with a rigid surface (Wilbeck [2]): (a) cylindrical impactor prior to impact; (b) shock wave propagating upwards and relief waves propagating inwards; (c) relief waves reached the axis of the cylinder; (d) end of the high pressure phase and beginning of flow phase of the impact

Figure 2: Spherical water drop at the end of the impact phase [15]

Figure 3: Impact of a spherical drop against a rigid surface: (a) contact radius expands faster than the speed of sound in water; (b) compressive wave front detaches from the rigid surface and relief wave propagates towards the inside of the compressed zone ; (c) outwards flow [15]

Figure 4: Stress waves propagating in the target following an impact

Figure 5: Effect of porosity on the pressure density behavior of birds 
Figure 6: Shock wave propagating with velocity $\mathrm{u}_{\mathrm{s}}$ in a medium that is initially at rest. (a) The particle velocity is zero ahead of the wave front and up behind it, (b) Particle velocities in a coordinate system moving with the wave front.

Figure 7: Unidirectional stress-strain curve for elastic-plastic material with strain hardening Figure 8: Pressure distribution for flat ended cylindrical bird model impacting a rigid plate Figure 9: Oblique impact on a rigid surface (Barber et al [41])

Figure 10: Slicing of a bird by turbofan blades in the direction of the relative velocity (Adapted from [128])

Figure 11: Generalized Maxwell viscoelastic model

Figure 12: Two degree of freedom model for canopy frame impact analysis [35]: $\mathrm{M}_{\mathrm{w}}$ and $\mathrm{k}_{\mathrm{w}}$ are the modal mass and stiffness of the first vibration mode of the canopy, $\mathrm{m}, \mathrm{k}$ and $\mathrm{C}$ are the equivalent mass, stiffness and stiffness coefficients of a supporting frame.

Figure 13: Tensor skin laminates

Figure 14: Viscoelastic model in which an applied stress produces an elastic strain $\varepsilon_{e}$, a viscous strain $\varepsilon_{v}$, and a delayed strain $\varepsilon_{d}$. 

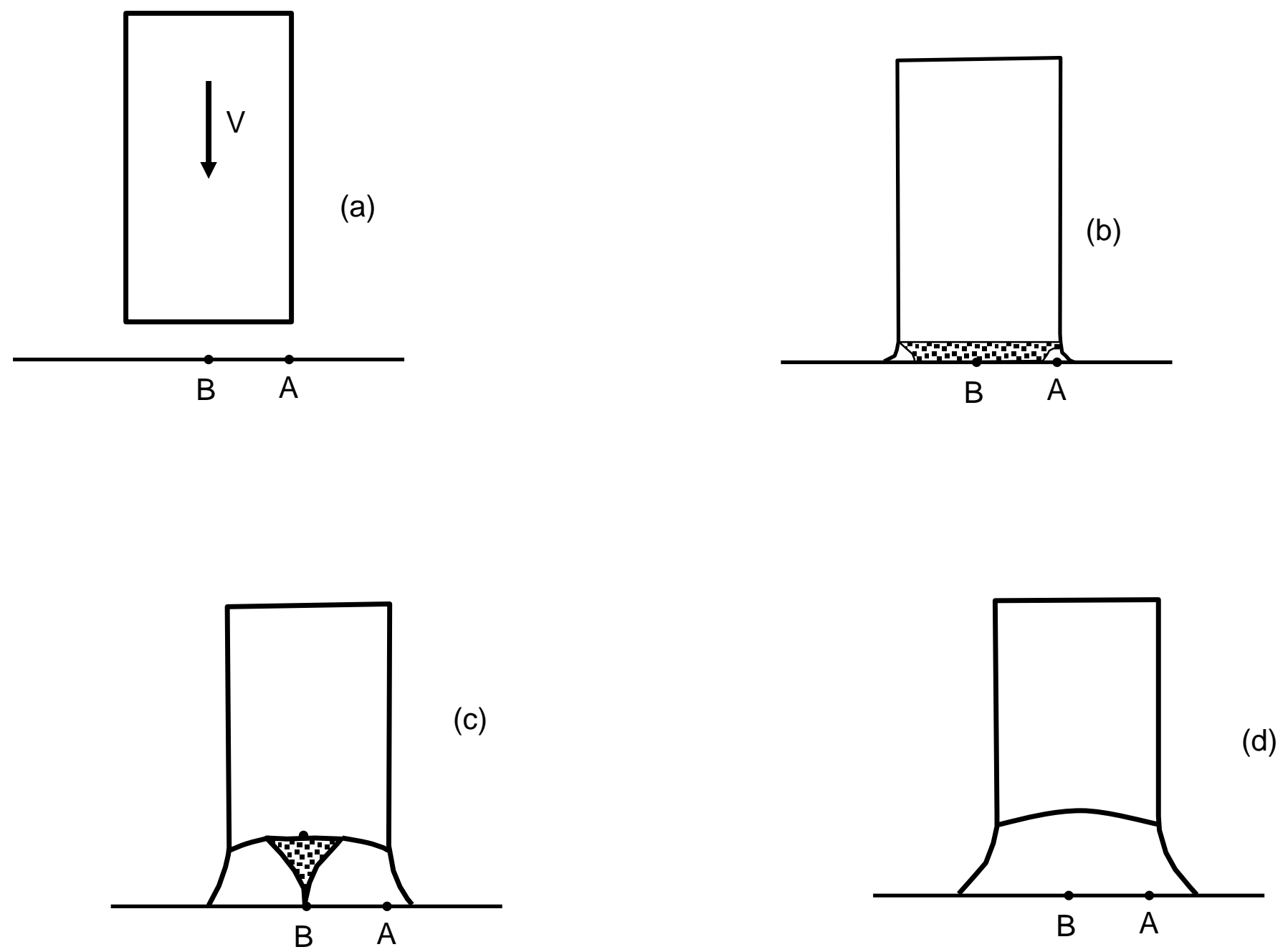

Figure 1 


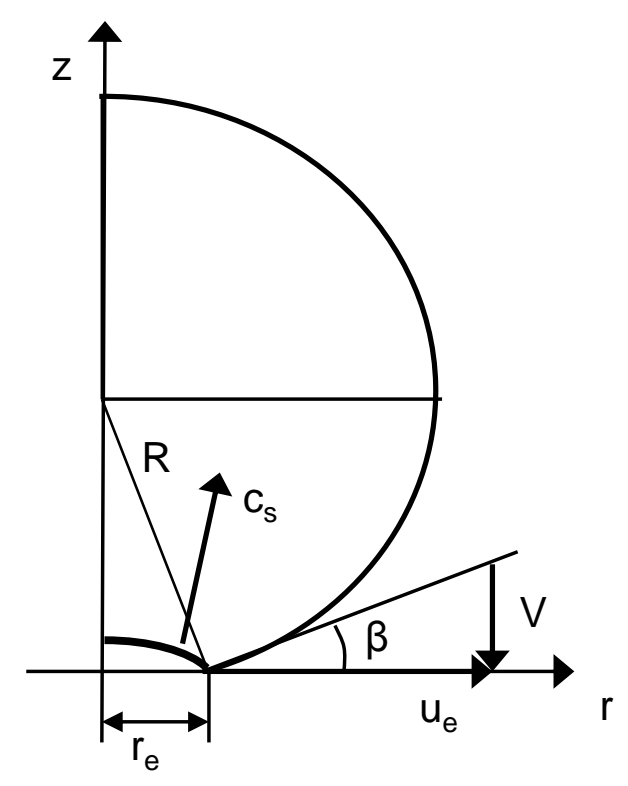

Figure 2 


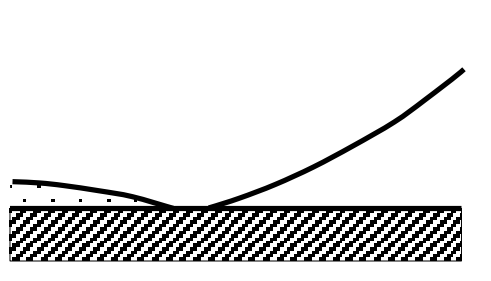

(a)

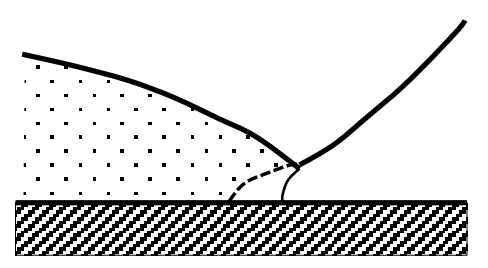

(b)

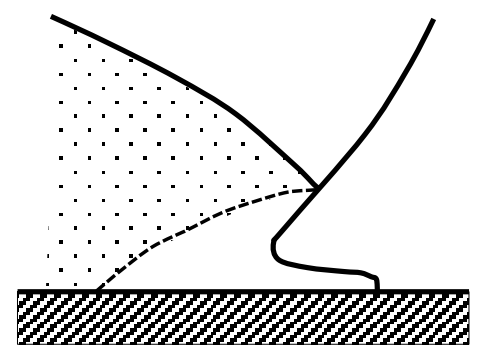

(c)

Figure 3 

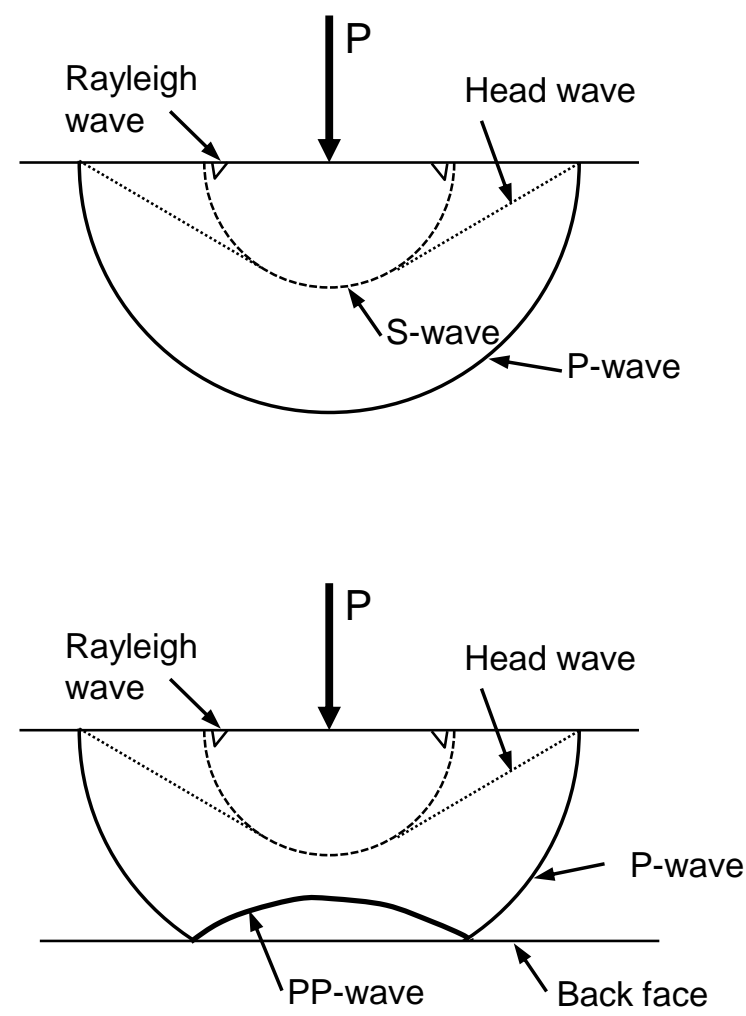

(b)

Figure 4 


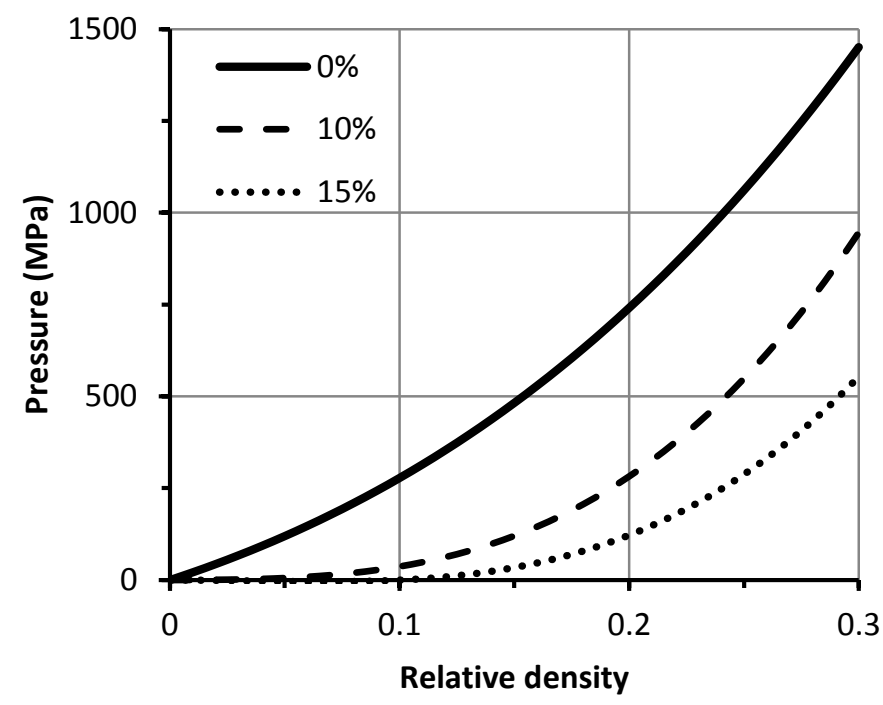

Figure 5 

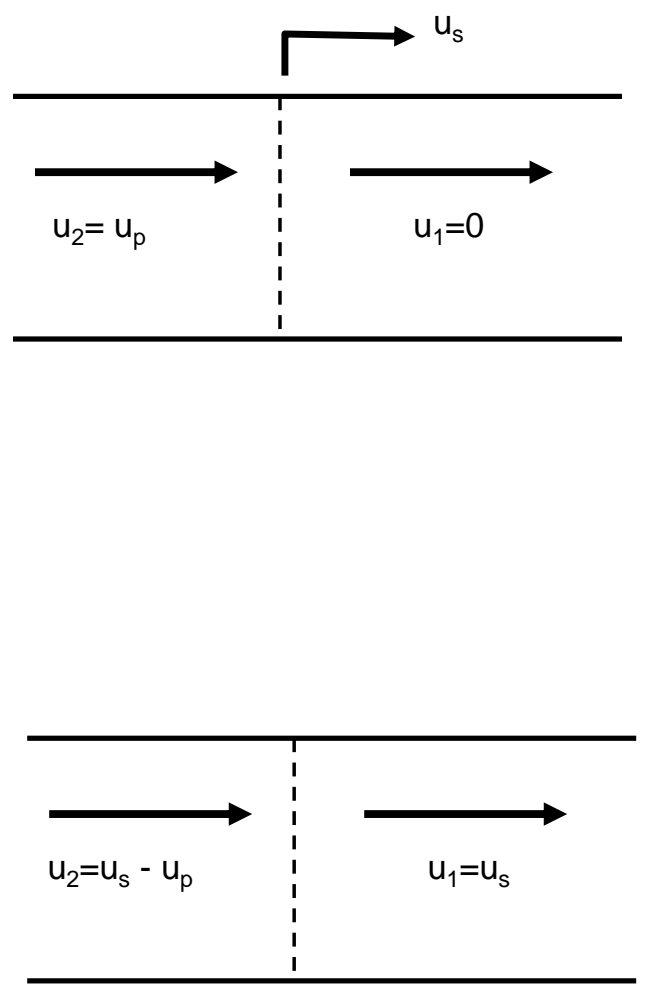

(b)

Figure 6 


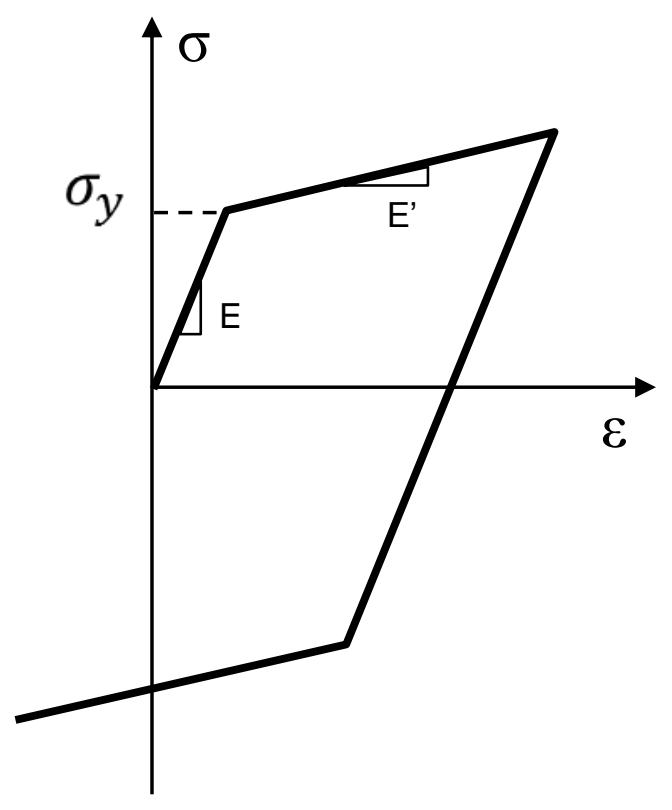

Figure 7: 


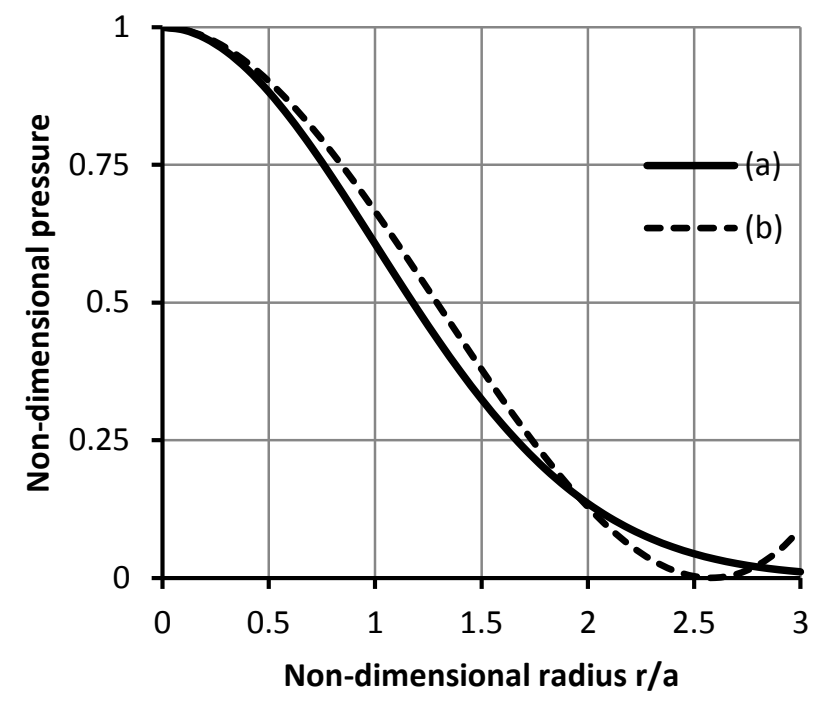

Figure 8 


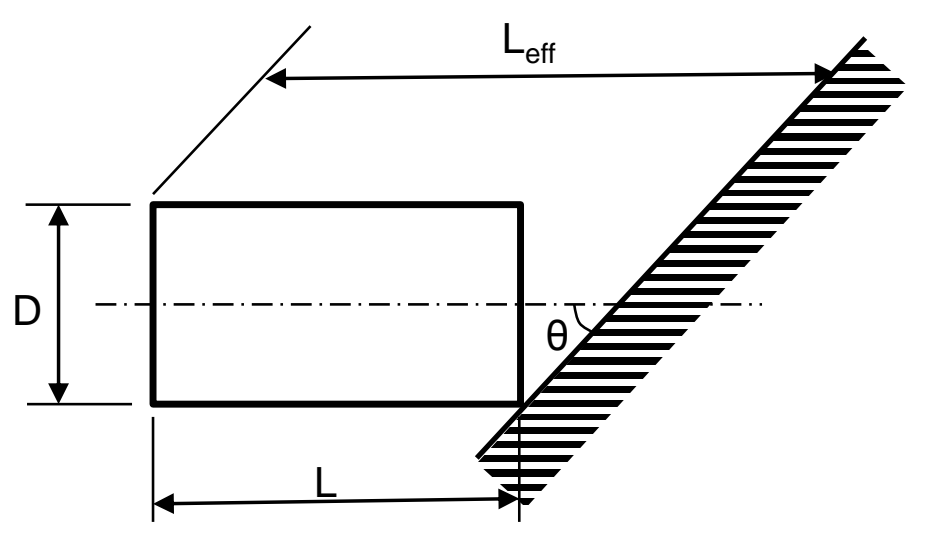

(a)

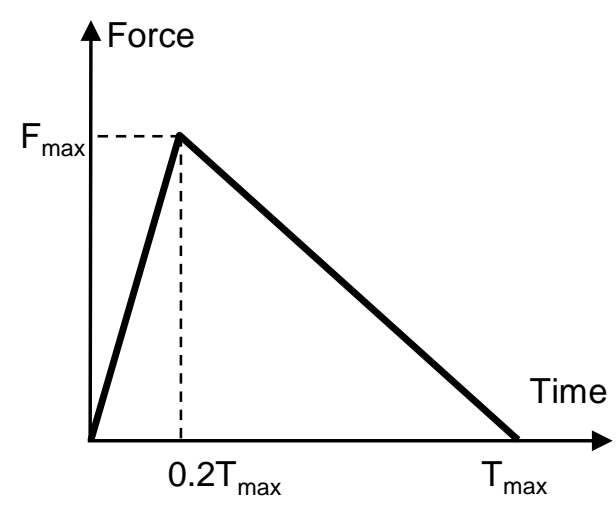

(b)

Figure 9 


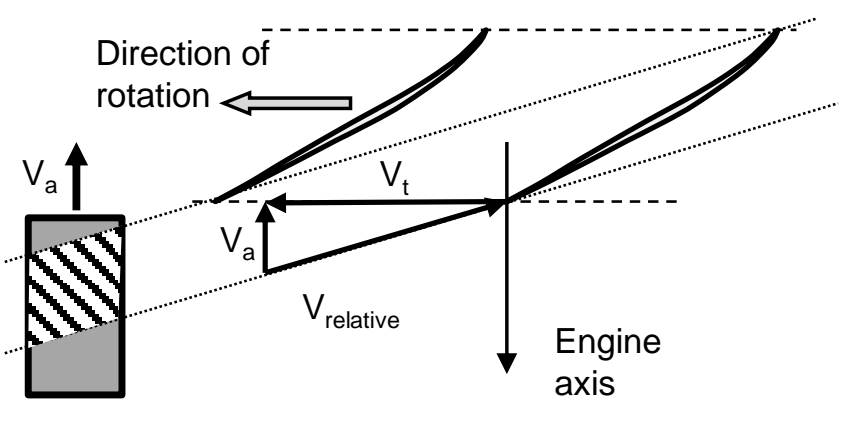

Figure 10 


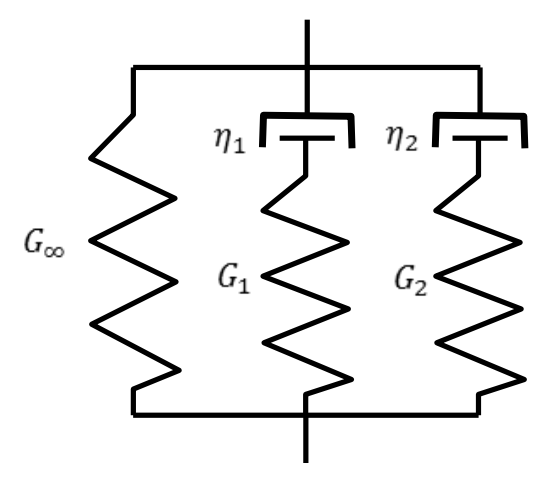

Figure 11 


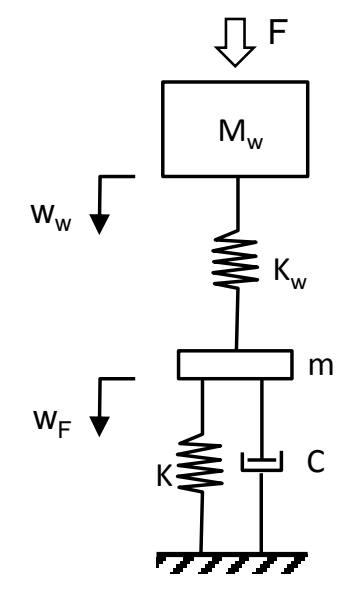

Figure 12 


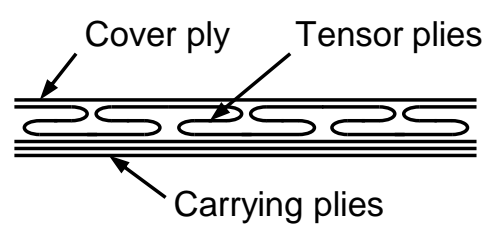

Figure 13 


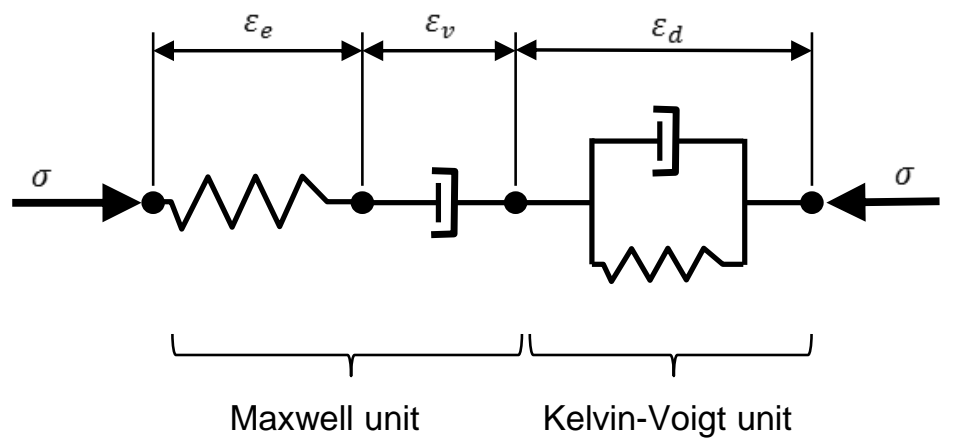

Figure 14 